\section{Jerome L. Stein}

Jerome L. Stein is professor of economics and Eastman protessor of political economy at Brown University.

\title{
Can the Central Bank Achieve Price Stability?
}

$\mathbb{T}_{\mathrm{HI}}$ to "foster price stability and promote sustainable growth in output." Can these objectives be achieved with the tools available? We know that there is a long-run relationship between the ratio $M / y=$ Money/real $G D P$ and the $P=G D P$ deflator of the form

(a) $P=V(M 2 / y)$

where $\mathrm{V}$ is the velocity function, shown in Figure 1. The Federal Reserve would like to select ranges for monetary growth over the coming year consistent with price stability. ${ }^{1}$ This is the policy of monetary targeting. The rationale for the policy of monetary targeting is the existence of a stable and reliable relationship between the rate of growth of monetary aggregate Mi [denoted $\mu_{i}(t)$ ] and the rate of inflation (denoted $\pi$ ) either during year $t$ or possibly $t+1$ of the form

(b) $\pi(t)=c+c^{\prime} \mu_{i}(t)$ or

(c) $\pi(t)=c+c^{\prime} \mu_{i}(t-1)$.
Equation (a) is a long-run relation between the price level and the stock of money per unit of real GDP and equations (b) and (c) are shorterrun relations between the rate of growth of prices and the rate of growth of money. They are quite different.

It has been amply demonstrated by monetarists that neither the growth of M1 nor of M2 produces a stable and reliable relationship of the form (b) or (c). ${ }^{2}$ The targeting of M1 was abandoned when the velocity function changed drastically after 1980 , and M2 targeting was then used. There was subsequent disappointment with targeting M2. Figure 2a-d shows why monetary targeting equations (b) and (c), either for M1 or M2, are not reliable. The source of the problem is the instability and unreliability of the velocity function (V1 for M1, and V2 for M2 in Figure 3a). This led Alan Greenspan (1993) to question the usefutness of M2 targeting [equation (b) or (c)]: ${ }^{3}$

"...the relationship between money [M2] and the economy may be undergoing a significant transformation....This is not to argue that money growth can be ignored in formulating monetary policy....Selecting ranges for monetary growth over the coming year consistent with desired
${ }^{1}$ By price stability, we mean a desired rate of change of prices, which need not be zero.

2See Belongia and Batten (1992), Thornton (1992), Gaffinkel and Thornton (1989), and Ritter (1993).
3The article by Ritter (1993), "The FOMC in 1992: A Monetary Conundrum," conveys the serious problems that arose when the FOMC tried to implement the policy of monetary targeting. 
Figure 1

GDP Deflator and the Ratio of M2/Real GDP

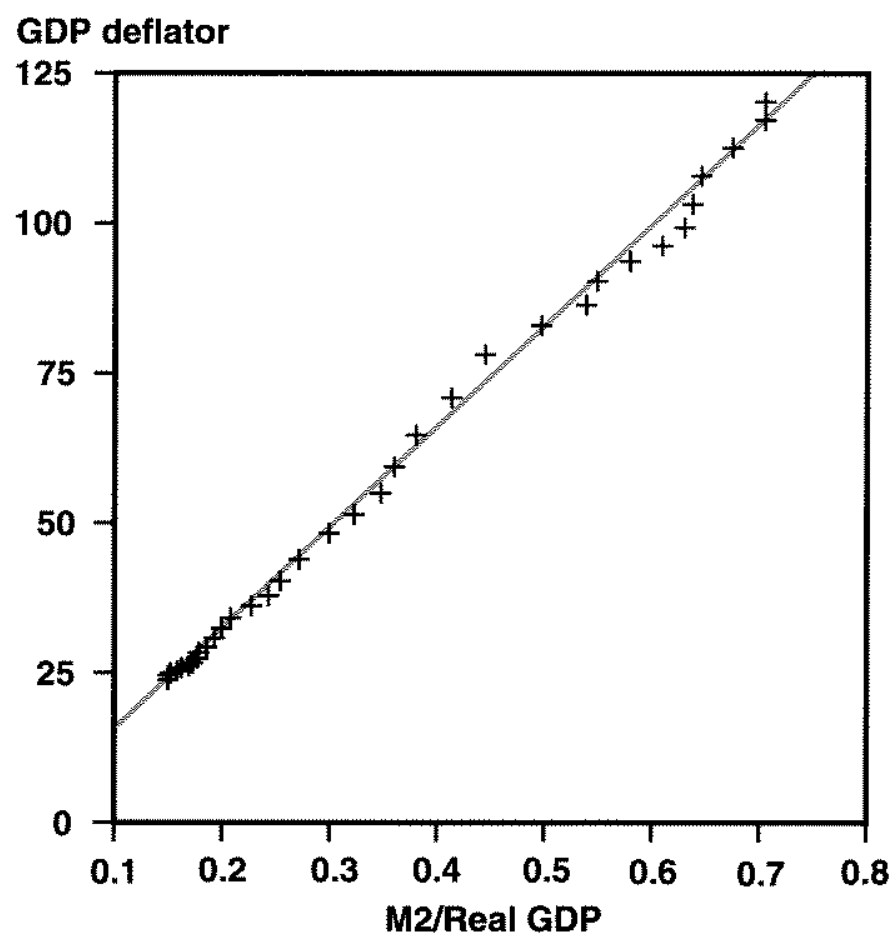

Figure 2a

Inflation and the Growth of M2

Inflation (change in GDP deflator)

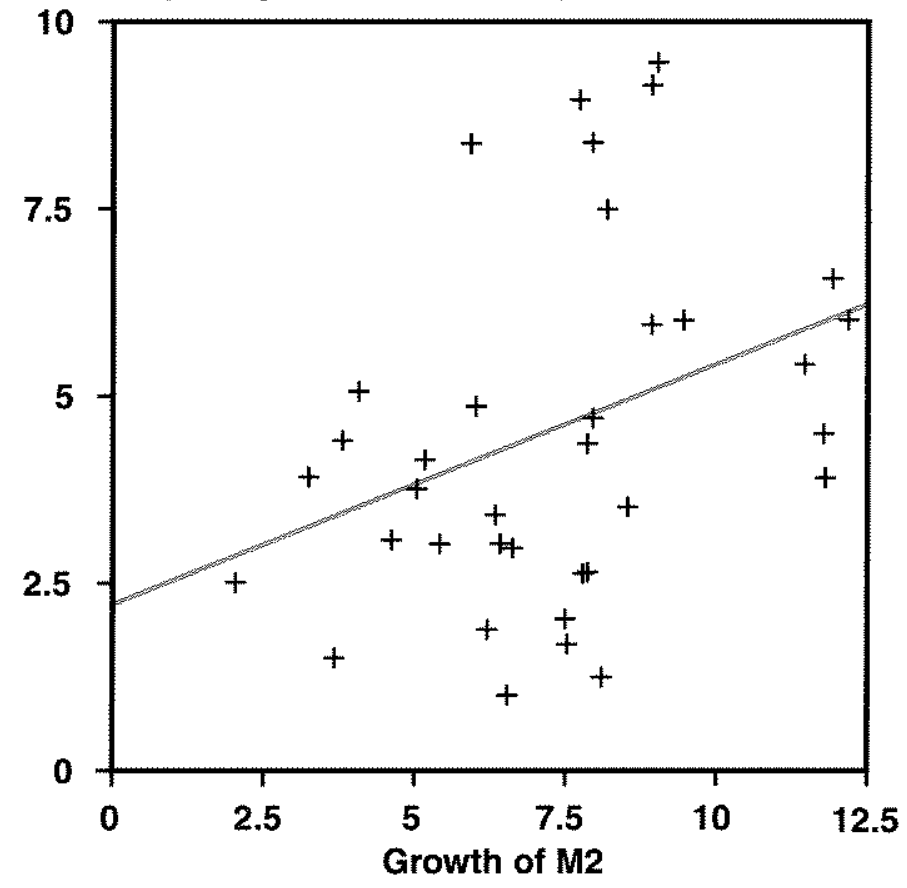


Figure $2 b$

Inflation and the Growth of M1

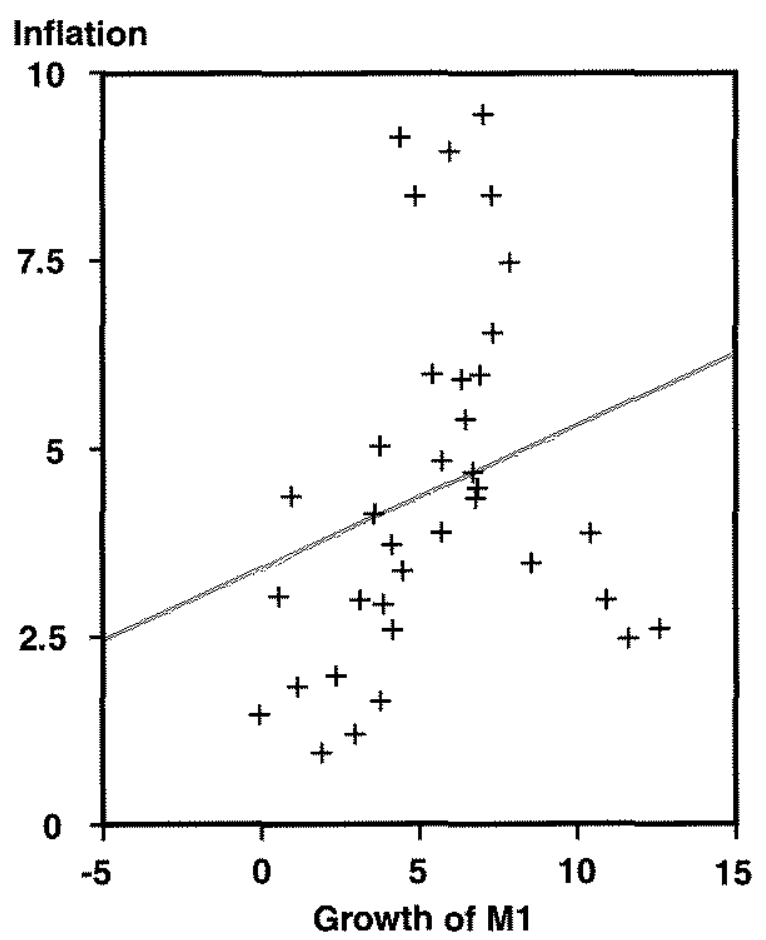

Figure 2d

Inflation and the Lagged Growth of M1

Inflation

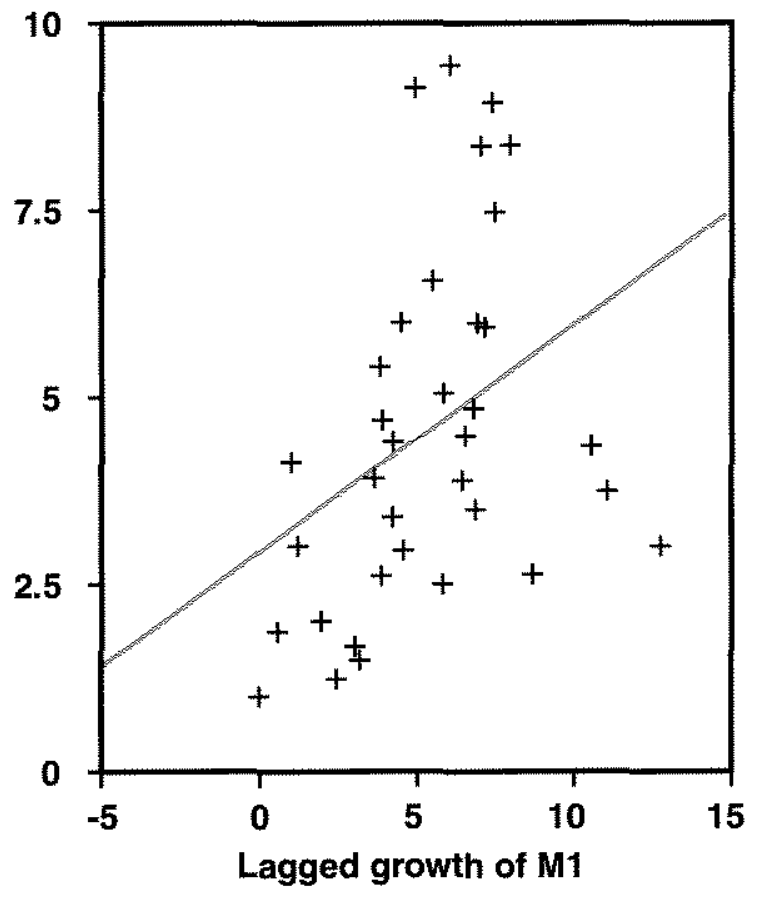

Figure 2c

Inflation and the Lagged Growth of M2

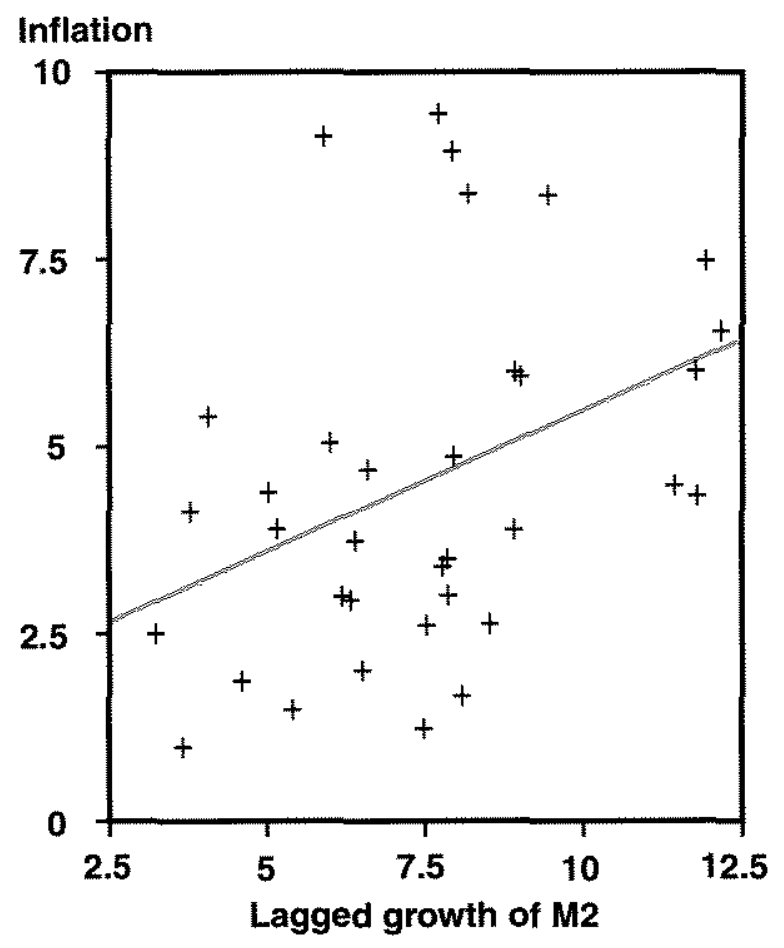

Figure 2e

Inflation and the Growth of Divisia M2

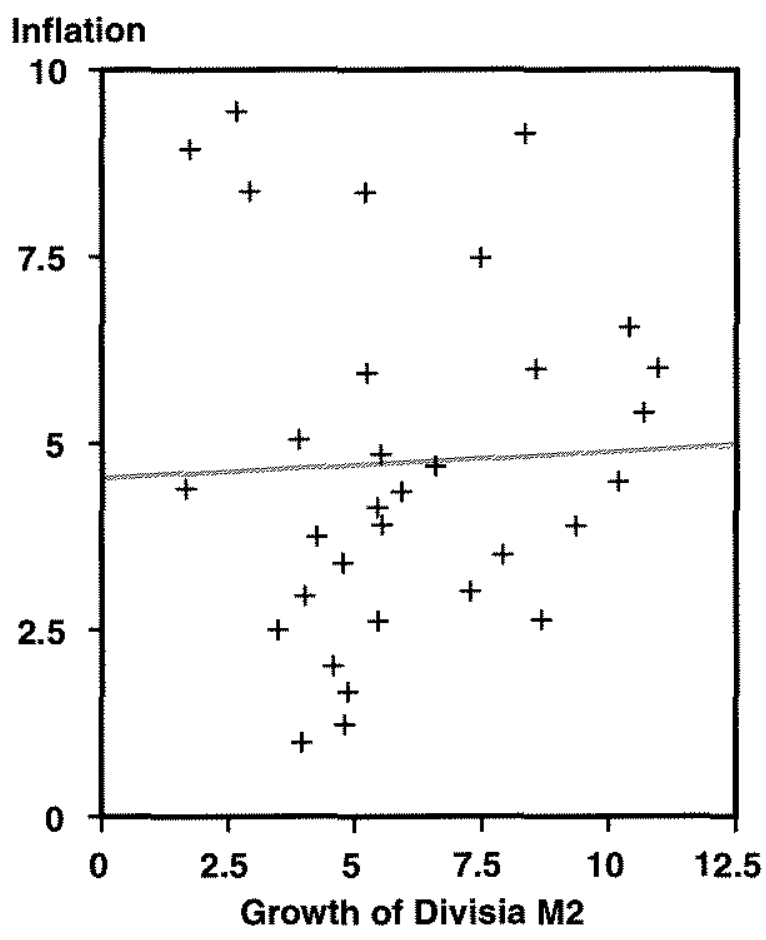


Figure 3a

Velocity of M1 and M2

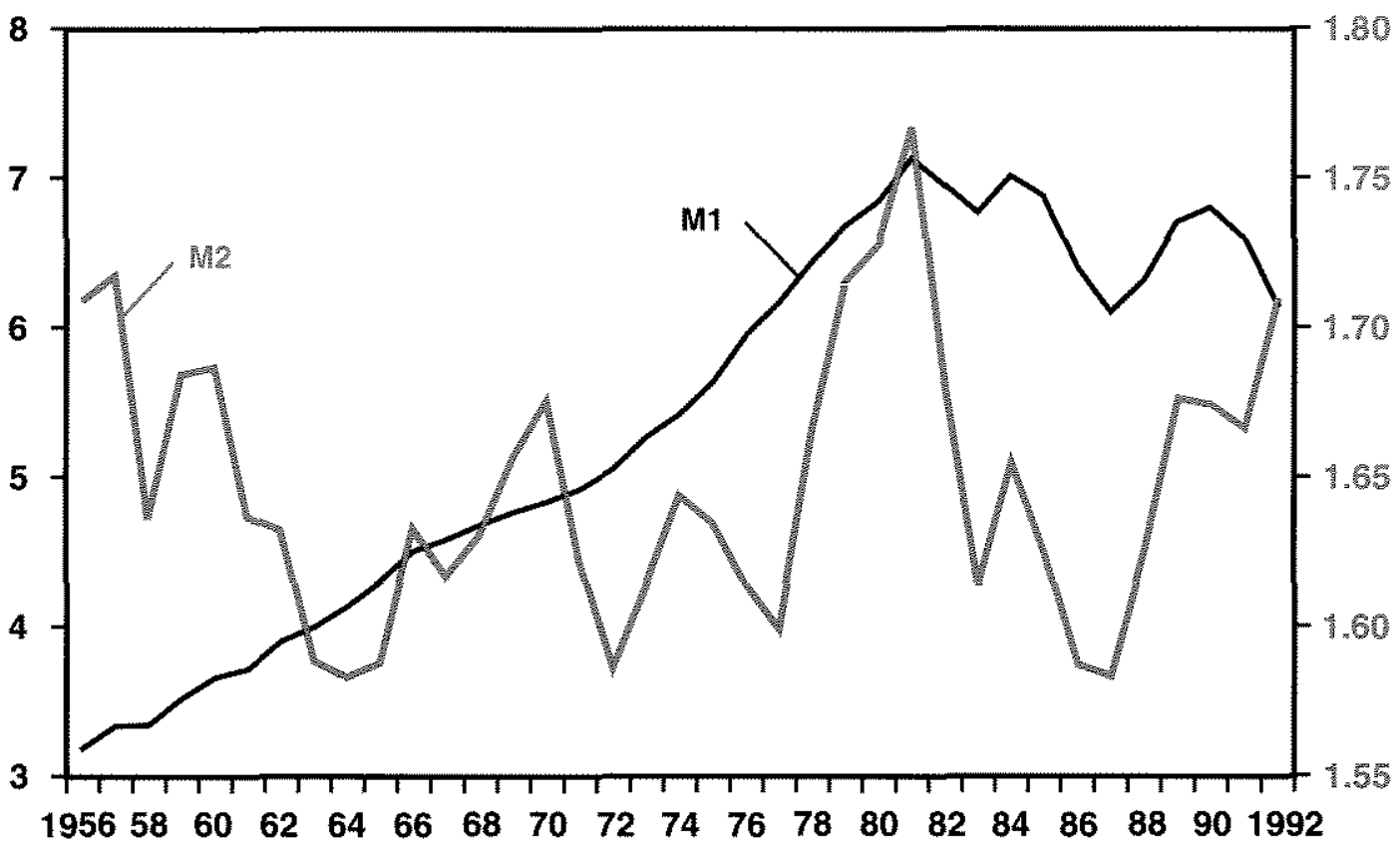

Figure $3 b$

Velocity of Divisia M2

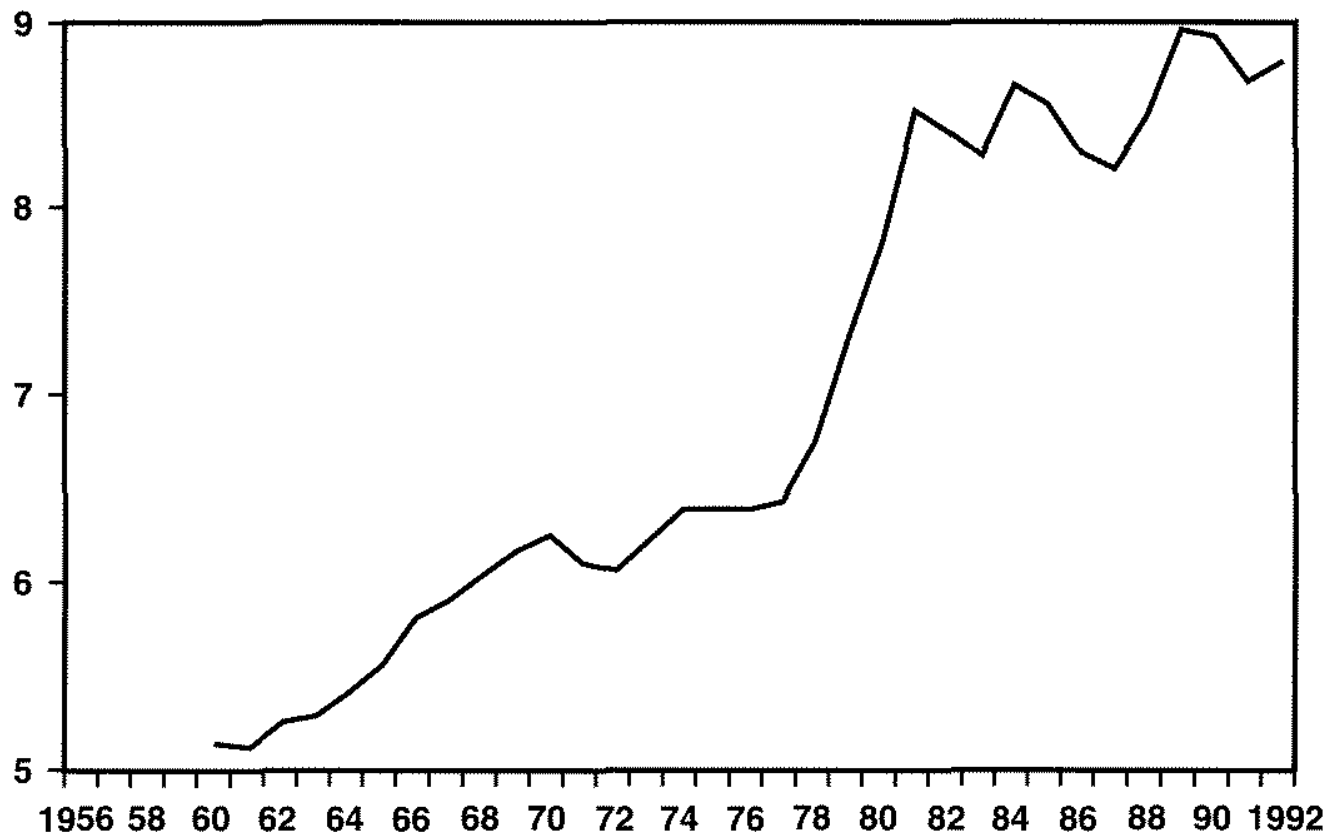


economic performance, however, is especially difficult when the relationship [velocity] between money and income has become uncertain. Recent experience suggests that...measuring money against such ranges may lead to erroneous conclusions regarding the stance of mone. tary policy."

Greenspan's disappointment with the use of monetary targeting (M2) has led him to revive the concept of interest rate targeting.

The ultimate question is how the central bank should try to produce price stability and sustainable growth. Our paper addresses several important questions:

1. Is there an economically significant, structurally stable, policy-rule-invariant relationship between the rate of growth of a monetary aggregate and the rate of growth of the price level? If so, that monetary aggregate is referred to as an indicator. What monetary aggregates, if any, qualify as indicators?

2. Which monetary aggregate is an intermediate target? An intermediate target is defined as a variable $Z$ which is an indicator and is also controllable over a range of policy regimes.

3. Under what conditions can Federal Reserve policy be used to speed the recovery and what will be the consequences for the rate of inflation?

4. Does the controllable Treasury bill rate qualify as an indicator or intermediate target?

Our major conclusions are:

A. The relation between the growth of the monetary aggregate and inflation is indirect. The change in the rate of inflation depends upon the unemployment rate and the growth of real balances which changes real aggregate demand. Neither the growth of M2 nor the growth of adjusted reserves per se conveys very much useful information about the course of inflation in the near future, because the inflation and unemployment rates interact in a dynamic manner. Within the context of the dynamic model, the growth of $\mathrm{M} 2$ is a good indicator of the rates of inflation and unemployment.

B. The growth of M2 has both an endogenous component and a directly controllable part. The link between the growth of M2 and reserve growth was tight from 1958-1975 and then became very weak from 1975-1992. Hence, the growth of M2 is primarily an indicator. The growth of adjusted bank reserves is an intermediate target for the rate of inflation, but less so for the unemployment rate, within the context of the dynamical system.

C. Weighted monetary aggregates are inferior to M2 as an indicator.

D. The nominal of "real" Treasury bill rate fails completely as an indicator, so it cannot be an intermediate target. ${ }^{4}$

The flow chart below describes the relation between the research design and the conclusions stated above. The Federal Reserve has been seeking a direct relation between the growth of monetary aggregate $\mathrm{Mi}$, where $D(\log M i)$ is denoted $\mu_{i^{\prime}}$ in a given year and the rate of inflation $D(\log P)=\pi$ in the subsequent year. ${ }^{5}$ We have seen that there is no direct relation between $\mu_{i}(t-1)$ and inflation $\pi(t)$. The reason is that the relation between inflation and money growth is indirect and works through a dynamic model. We first derive the structural equations of a dynamical system involving the state variables $X$, which are the inflation $(\pi)$, the anticipated inflation $\left(\pi^{*}\right)$ and unemployment rates $(u) .^{6}$ The input is the rate of growth of a monetary aggregate $\mu=D M / M$. The resulting reduced form system (the $\mathrm{SM}$ dynamical system) is of the form $D X=A X+B \mu+e^{\prime}$, described in Table 1 or the flow chart below?

$$
\begin{array}{r}
\text { SM dynamical model } \\
\begin{array}{c}
X \leftarrow D X=A X+B \mu+e^{\prime} \\
\text { indicator }
\end{array}
\end{array} \quad \frac{\text { money growth }}{\text { control }}
$$

${ }^{4}$ An intermediate target is an indicator, but not necessarily the reverse.

${ }^{5}$ For economy of notation throughout the paper, the operator $D$ represents either the discrete first difference operator $D x=x(t)-x(t-1)$ or the continuous time derivative $D x=d x / d t$ as appropriate in the context.

\section{The unemployment rate $u(t)=U(t)-U e$ is the deviation be- tween the measured unemployment rate $U(t)$ and the equilibrium level $U_{e}$}

${ }^{7} \mathrm{SM}$ denotes the Stein Monetarist dynamical model as developed in Stein (1982). 


\section{Table 1}

The Reduced-Form Equations for the Dynamics of Inflation and Unemployment, from the SM Model

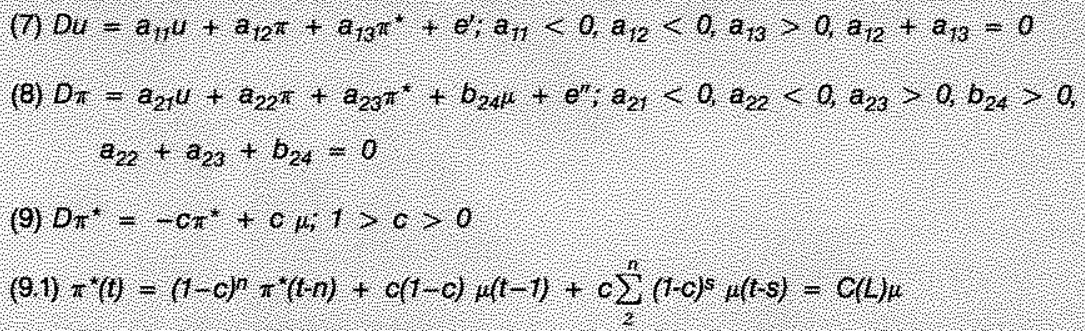

We estimate a surrogate of the SM dynamical model, in which the dependent variables $X$ are the observable unemployment and inflation rates. The equations of the surrogate model are:

$$
\begin{aligned}
\pi(t)-\pi(t-1)= & b_{0}^{\prime}-b_{1}^{\prime} U(t-1)+b_{z}^{\prime}[\mu(t-1) \\
& -\mu(t-1)]+e_{1} ; \\
U(t)-U(t-1)= & a_{0}^{\prime}-a_{1}^{\prime} U(t-1) \\
& -a_{2}^{\prime}[\mu(t-1)-\pi(t-1)]+e_{2} ; \\
E\left(e_{i}\right)= & 0 .
\end{aligned}
$$

The effect of the growth of the monetary input $\mu$ upon the rate of inflation is indirect: It operates through the dynamical system, which also involves the unemployment rate. The change in the rate of inflation depends upon the unemployment rate and the rate of change of real balances $(\mu-\pi)$. The change in the unemployment rate depends upon its level and the change in real balances. We have already seen that there is no direct relation between the rate of monetary expansion $\mu(t-1)$ and the subsequent rate of inflation $\pi(t)$. However; when we consider how the rate of M2 monetary expansion $\mu(t-1)$ operates upon the dynamical system, implied by the structural equations, the growth of $\mathrm{M}_{2}$ is a very good indicator of the subsequent rates of inflation and unemployment. The matrices A and B are structurally stable and policy-rule invariant; and the surrogate system is a good predictor. This is conclusion A above, that the growth of $\mathrm{M} 2$ is a good indicator. We show that the growth of $\mathrm{M} 2$ is better than alternative monetary aggregates (conclusion $\mathrm{Cl}$.
We then consider the intermediate target issue: To what extent is the growth of M2 controllable? This is the next link in the flow chart: $\mu=C X+$ $b z+e^{\prime \prime}$. The rate of monetary expansion $\mu$ has two components. One component is the growth of reserves $z$ which is controllable. The other component is $C X$, the induced part of the growth of $\mathrm{M} 2$, which responds to the state of the economy. We estimate this relationship. From $1958-75$, the growth of M2 was determined by the controllable growth in reserves. After 1975, and especially after 1984, the growth of reserves did not have that effect and the growth of M2 was endogenous. The reason is that the growth of the non-M1 component of M2 was not controllable by the growth of reserves (conclusion B). The growth of M2 was an intermediate target prior to 1975, and much less so afterwards.

Combining the two links, we ask whether the controllable growth of reserves $z$ operates through the dynamical system, of the following form:

$X<--D X=(A+B C) X+(B b)_{Z}+\left(B e^{\prime \prime}+e^{\prime}\right)<--m-Z$

intermediate target

control variable

The answer is that this system is acceptable for the inflation rate and less so for the unemployment rate in recent years. This is in conclusion B. Finally, we ask whether the controllable Treasury bill rate operating through the dynamical system can be considered to be an intermediate target. Conclusion $D$ is that there is no informational content to the controllable Treasury bill rate. It is neither an indicator nor an intermediate target. 


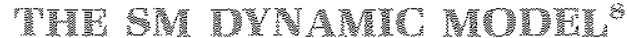

\section{rran}

There are five structural equations and one identity to the SM dynamic model. First: The rate of inflation $\pi=D p / p$ depends upon the excess demand for goods, $J(t)=$ aggregate real demand less current real GDP, and the rate of growth of unit labor costs $D W / W$, where $W$ is unit labor costs. This is equation 1 , where $D=d / d t, \gamma$ is a parameter:

(1) $\pi=D W / W+\gamma J$

Second: The growth of unit labor costs depends upon the state of the labor market, reflected by the deviation between the unemployment rate $U(t)$ and its equilibrium rate $U e_{\text {, }}$ and by the anticipated rate of inflation $\pi^{*}$. This is equation 2. That is, the anticipated rise in the real unit labor costs depends negatively upon the excess supply in the labor market, where the excess supply is reflected in the unemployment rate.

\section{(2) $D W / W=\pi^{*}-h(U(t)-U e]$}

Equation 3 simply states that the observed unemployment rate is positively related to the unobserved excess supply of labor. The demand for labor depends negatively upon real unit labor costs, and the supply of labor has an algebraically greater relationship with the real unit labor costs than does the demand. Hence, the observable unemployment rate, which is positively related to the unobservable excess supply of labor, depends positively upon real unit labor costs $W / P$.

(3) $U(t)=b_{0}+b_{1} \ln (W / P)$

The real excess demand for goods $J(t)=$ real aggregate demand less real GDP is equation 4 , when we have solved for the equation, which

8This is explicitly developed in Stein (1982), and Infante and Stein (1980). Here, we attempt to simplify and focus exclusively upon the basic characteristics. The SM refers to my version of a monetarist system. The techniques of analysis are different from conventional monetarists since the velocity function is not used and the SM model involves an in. teraction of unemployment and inflation. The conclusions, however, are quite close to those of Friedman, hence the term monetarist. In a sense, the SM dynamic model lies between the thinking of Friedman and Tobin.

"This is discussed in equation 19 in connection with the intermediate target. produces portfolio balance. ${ }^{9}$ In terms of the usual Keynesian 45-degree diagram, $J$ is the vertical distance between aggregate demand and current real GDP (the ordinate on the 45-degree line). The basic parameter of the aggregate demand curve is real balances per unit of capacity output. Hence, the excess demand for goods depends upon the unemployment rate (which is negatively related to the ratio of actual to capacity output), real balances $m(t)=M / P Y^{*}$ per unit of capacity output $Y^{*}$ and disturbances $\eta(t)$.

(4) $\gamma J(t)=J(U, m ; \eta)=J_{1} U+J_{2} \ln (m)$

$$
+\eta, J_{i}>0 \text {. }
$$

Substitute equations 2 and 4 into equation 1 to obtain 1.1. It is clear that the inflation equation is not the usual expectations augmented Phillips curve, since it contains the real balances as variables as well as the unemployment rate and rate of anticipated inflation.

$$
\text { (1.1) } \pi=\pi^{*}-h(U-U e)+\gamma J_{1} U+J_{2} \ln (m)+\eta
$$

The anticipated rate of inflation slowly converges to the trend rate of monetary growth per unit of output, equation 5 . Variable $\mu(t)$ is the rate of monetary growth and $n$ is the trend rate of growth of output. There are two established facts:

(a) There is a long-run, positive relation between the price level and some monetary aggregate (Figure 1), and

(b) On a year-to-year basis, there is no reliable relationship $\pi=c+c^{\prime} \mu$ between money growth and the subsequent rate of inflation (Figure 2). That is, there is very little informational content in the current rate of monetary expansion concerning the rate of inflation in the near future. ${ }^{10}$

In our Bayesian framework, there is a prior anticipated rate of inflation $\pi^{*}(t){ }^{11}$ Then, there is

10We have no need to use the subjective concept of anticipated or unanticipated money growth.

11 We use the concept of Asymptotically Rational Expectations as developed in Stein $(1992 a, b)$. Our results are not sensitive to the specific form of the anticipated inflation equation. Any anticipations function that satisfies the following conditions will suffice. First, in the steady state, a change in the rate of monetary expansion changes actual and anticipated infiation by the same amounts. Second, a change in the rate of monetary expansion at time t does not change the current rate of anticipated inflation by as much. 
Table 2

The Surrogate System: Estimated Inflation and Unemployment Equations

\begin{tabular}{|c|c|c|c|c|}
\hline Vatable & $\begin{array}{l}\text { Gro } \\
\text { Inilation }\end{array}$ & Unemp U & Intlation 1 & Unemp 4 \\
\hline constant & $1,4[0,1]$ & $196[000]$ & $16[006)$ & $1.6[001]$ \\
\hline $4(-1)$ & $-0,39[00]$ & $0.76[000]$ & $-034[0,016]$ & $069[000)$ \\
\hline$\pi(t-1)$ & $086[0.00]$ & 0,2910001 & $092(0.00)$ & $023[000]$ \\
\hline$(t-1)$ & $0.21[0.03]$ & $0.231000]$ & -3 & ४ै। \\
\hline $2(-1)$ & ?ै? & +3 & $016[002]$ & $-0,13[0.01]$ \\
\hline $\mathrm{ADJRSO}$ & 077 & 076 & 078 \& & 0.71 \\
\hline U prob $\mathrm{A}$ & 007 & 072 & 018 & 072 \\
\hline
\end{tabular}

Notes, Sample period 1959-92, annual, $N=35$. Columns one and two fefer to equations 10 and 11 for growth of M2, columns three and tour refer to equations 12 and 13 tor growth of reserves The two-tall significance level is showh hn brackets.

current information, which is the current rate of monetary expansion $(\mu(t)-n l$. Combining the two, the posterior anticipated inflation $\pi^{*}(t+1)$ $=(1-c) \pi^{*}(t)+c(\mu(t)-n)$, is a linear combination of the prior and the current information. The coefficient $c$ is the weight given to the current sample of information. Subtract the prior from both sides and derive:

$$
\text { (5) } \begin{aligned}
D \pi^{*} & =\pi^{*}(t+1 ; t)-\pi^{*}(t) \\
& \left.=c / \mu(t)-n-\pi^{*}(t)\right)
\end{aligned}
$$

The "credibility" argument is contained in the value of coefficient $c$. If the public believes that the central bank is committed to an inflation target [the prior $\left.\pi^{*}(t)\right)$, then variations in the current rate of monetary expansion $[\mu(t)-n]$ will be given a low weight and coefficient $c$ will be small. Coefficient $c$ reflects the predictability that the current rate of monetary growth will continue for a long time and the tightness of the relation between money growth and inflation over the relevant horizon.

The rate of growth of real balances relative to the trend rate of growth of output $n$ is equation (6), which closes the system.

(6) $D m / m=\mu-\pi-n$.

These dynamic interactions between the inflation rate, unemployment rate and monetary polim cy must be explicitly considered if we are to answer the questions posed at the beginning of this paper: Specifically, what is an indicator and what is an intermediate target? Equations 1-6 are solved in the dynamic form described by
Table 1. These differential equations imply the steady-state relations as well as the medium-run dynamics. The steady-state solution is that: The unemployment rate converges to the equilibrium rate. The latter is independent of monetary factors. The actual and anticipated rates of inflation converge to the growth of the money supply (or growth of the money supply less the long-term growth rate of the economy). Equation 5 or 9 may be solved to vield equation 9.1 in Table 1. The anticipated rate of inflation at any date $t$ is a weighted sum of past rates of monetary $\mathrm{ex}$ pansion, with declining weights.

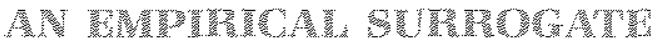 9}

The system described in Table 1 involves the measured unemployment and inflation rates and the nonobservable anticipated rate of inflation. For empirical analysis, we convert the SM dynamic model in Table 1 into a surrogate system, involving measurable quantities only. These, in the form of equations 10 and 11 below, are used for empirical estimation in Table 2. The sur. rogate system mimics the dynamical system. First we explicitly derive, from equations $1-6$ of the SM model, the reduced form equations in Table 1. Then we show how the surrogate system is derived from the SM model.

Differentiate equation 3 with respect to time and use 2 to obtain 7 :

(7) $\begin{aligned} D u & =b\left(\pi^{*}-h u-\pi\right)+e^{\prime} \\ & =a_{n} u+a_{12} \pi+a_{13} \pi^{*}+e^{\prime}\end{aligned}$ 
Differentiate 1 with respect to time, using 4-7 to obtain equation 8 . The constraints on the coefficients follow from definitions of $a_{i j}$ and $b_{i j}$;

$$
\text { (8) } \begin{aligned}
D \pi= & -h b\left(J_{1}-h\right) U-\left[\left(J_{1}-h\right) b+J_{2} J \pi\right. \\
& +\left[\left(J_{1}-h\right) b-c\right] \pi^{*}+\left(J_{2}+c\right)(\mu-n)+e^{\prime \prime} \\
= & a_{21} U+a_{22} \pi+a_{23} \pi^{*}+b_{24}(-n)+e^{\prime \prime}
\end{aligned}
$$

Equation 9 is equation 5 above:

(9) $D \pi^{*}=-c \pi^{*}+c \mu$

The continuous time dynamical system $7-9$ in Table 1 may be written as $D X=A X+B \mu+e$, where $X=\left(u, \pi, \pi^{*}\right)$. We use $e$ as a generic representation of a random variable with a zero expectation.

In this paper, we use annual rather than quarterly data because we obtained clear-cut, significant results with annual data (Table 2), whereas nothing of economic significance emerged when we used the noisy quarterly data, as shown in the appendix. When the data are annual and one just uses the observable $U$, $\pi$ and $\mu$ the surrogate empirical system is equations 10 and 11 .

$$
\begin{aligned}
(10) \pi(t)= & b_{0}+b_{1} U(t-1)+b_{2} \pi(t-1) \\
& +b_{3} \mu(t-1)+e^{\prime} \\
& H_{0^{*}} b_{2}+b_{3}=1 ; b_{1}<0 \\
\text { (11) } U(t)= & a_{0}+a_{1} U(t-1)+a_{2} \pi(t-1) \\
& a_{3} \mu(t-1)+e^{\prime \prime} ; \\
& H_{0}: a_{2}+a_{3}=0_{;} a_{3}<0
\end{aligned}
$$

There are two important theoretical con. straints concerning monetary neutrality. Equal rises in money growth and inflation do not

"2This can be seen as follows. The estimates (from Table 2) of the sutrogate system 10 and 11 are 10.1 and 11.1. The SM model (Table 1) can be written as (A.1)-(A.3) when the following values are used. The half-life of the deviation of: (i) the inflation rate from its equilibrium value is two years, (ii) the unemployment rate from its equilbrium value is 3.5 years and (iii) anticipated inflation from its equilibrium is tive years. This gives us the coefficients in the principal diagonal of matrix A. (ii) The effects of inflation and anticipated inflation upon the change in unemployment and the change in inftation are equal and opposite (see equations 7,8 ). (iii) All variables are measured as deviations from their steady-state values. Then the SM dynamic system is:
(A.1)
$D_{\pi}=-.197 \pi$
$-.14$
$+.197 \pi^{*}$
(A.2) $\quad D u=-1 \pi$
$-.3470$
$+1 \pi^{*}$
(A.3) $D_{\pi^{*}}=-.138 \pi^{*}$

change real balances and, hence, have no effect upon the unemployment rate. Similarly, in the steady state, the actual and anticipated rates of inflation will change by as much as the rate of monetary expansion. One is not free to construct any monetary aggregate as either an indicator or an intermediate target simply on the grounds that it seems work over the period considered. Instead, the monetary aggregate must be closely linked to the theory, such that the variable satisfies certain neutrality constraints. The neutrality constraints in the indicator system are as follows. In a comparative steady state, money and prices change by the same proportion, there is no effect upon the unemployment rate. The constraint in inflation equation 10 is that in the steady state a change in the rate of monetary expansion will change the actual and anticipated rates of inflation by the same amount: $b_{z}+b_{3}=1$. The constraint in unemployment equation (11) is that, when money and prices change by the same amount, there is no effect upon real unit labor costs and no change in the unemployment rate: $a_{2}+a_{3}=0$.

With these constraints, the surrogate system 10 and 11 mimics the SM dynamic system, Table $1^{12}$

Regarding equations $7-9$ or 10 and 11 , a rise in the rate of monetary expansion relative to the initial rate of inflation has several effects. First, it raises real balances which raises aggregate demand. The rise in aggregate demand raises the rate of inflation. Second, the rise in the rate of monetary expansion raises the anticipated rate of inflation (by coefficient $c$ in equation 5 or 9 above). The rate of growth of the nominal wage will rise, by the anticipations effect in equation 2 above. This effect will not be great because a

Surrogate system (estimates from Table 2, rounded)

$\begin{array}{ll}(10.1) & \mathrm{D}_{\pi}=-.2 \pi-.4 u \\ (11.1) & \mathrm{D} u=.25 \pi-.3 u\end{array}$

Let the initial conditions, corresponding to points $B$ and $C$ in phase-diagram Figure 8 be as follows for the two systems.

\begin{tabular}{lrrrr} 
& \multicolumn{2}{c}{ SM } & \multicolumn{2}{c}{ Surrogate system } \\
& $B$ & $C$ & $B$ & $C$ \\
$\pi(0)$ & -2 & 0 & -2 & 0 \\
$u(0)$ & 2 & -2 & 2 & -2 \\
$\pi^{*}(0)$ & -2 & 0 & &
\end{tabular}

The trajectories of the inflation and unemployment variables are very similar. 
rise in the current rate of monetary expansion will convey little information about the rate of inflation, as is seen in Figure 2. The net effect will be that the rate of inflation will rise, as a result of both the rise in aggregate demand due to the rise in real balances, and the rise in the growth of nominal unit labor costs. However, real unit labor costs will decline and unemployment will decline. These are the short-run effects. As time proceeds, the decline in unemployment and a rise in the rate of anticipated inflation will raise real unit labor costs and the unemploy. ment rate will converge to its equilibrium rate.

Later, we shall consider the intermediate tar get system, equations 12 and 13 , where the input is the growth of reserves $z$.

$$
\begin{aligned}
(12) \pi(t)= & b_{0}^{\prime}+b_{1}^{\prime} U(t-1)+b_{2}^{\prime} \pi(t-1) \\
& +b_{3}^{\prime} z(t-1)+e^{\prime} ; \\
& H_{0}: b_{2}^{\prime}+b_{3}^{\prime}=1 ; b_{1}^{\prime}<0 \\
\text { (13) } U(t)= & a_{0}^{\prime}+a_{1}^{\prime} U(t-1)+a_{2}^{\prime} \pi(t-1) \\
& +a_{3}^{\prime} z(t-1)+e^{\prime \prime} ; \\
& H_{0}: a_{2}^{\prime}+a_{3}^{\prime}=0 ; a_{3}^{\prime}<0
\end{aligned}
$$

We ask in the next section whether, within the context of the dynamical system, there are economically significant (the neutrality constraints are satisfied), structurally stable, policy-invariant relations equations 10 and 11 . When the input $\mu(t-1)$ is the growth of $\mathrm{M} 2$, the answer to all of these questions is yes, and there is no change in the values of the coefficients even when policy changed drastically.

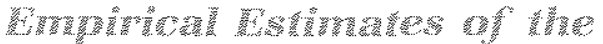

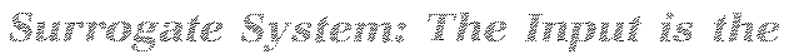 Crisy}

Table 2 summarizes the empirical results for both equations 10 and 11, where the input is $\mu$ the growth of $\mathrm{M} 2$, Column one refers to inflation equation 10, column two refers to unemployment equation 11.t4 In each cell is the value of the regression coefficient and, in brackets, the two-tail significance level. Summary and diagnostic statistics are at the end of the table and in the text.

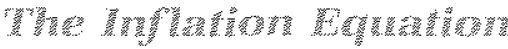

Table 2, column one, describing SM inflation equation 10 indicates that the growth of $\mathrm{M} 2$ is a good indicator, within the context of the secondorder dynamical system. The coefficients have the hypothesized and statistically significant signs, satisfy the theoretical constraints, have remarkable structural stability despite changes in policy rules, and this equation has considerable predictive accuracy.

First, each coefficient in column one has the hypothesized sign and is significantly different from zero. The coefficient of the lagged unem. ployment rate $b_{i}=-0.39$, with a two-tail significance level of 0.01 ; the coefficient of the lagged M2 growth $b_{3}=0.21$ with a significance level of 0.03 . The coefficient of the lagged inflation $b_{2}=0.86$ with a significance level of 0.00 .

Second, the neutrality requirement is satisfied. The Wald test concerns the neutrality hypothesis that $b_{2}+b_{3}=1$ : In the steady state a rise in the rate of monetary expansion raises the rate of inflation by the same amount. The sum of these coefficients is not significantly different from unity: the probability $\left[b_{2}+b_{3}=1\right]=$ probl. $86+.21=1]=0.52$.

Third, there are some mixed results concerning equation evaluation tests. There is no strong evidence of serial correlation of the residuals. The LM/Breusch-Godfrey statistic tests whether the lagged residuals add to the explanatory power of the equation. The hypothesis that the coefficients of all of the lagged residuals are zero has a probability of 0.07 . The Ramsey RESET test indicated that there seems to be no specification error in the formulation of the inflation equation. The ADF statistic for the stationarity of the residuals was -2.4 , which is a bit low to maintain the stationarity hypothesis. The ARCH test statistic allows us to reject the hypothesis of heteroskedasticity.

Fourth, is the issue of structural stability and predictability, during a period when there were changes in the policy rule. There is no single, commonly accepted break point for the policy rule change. Structural stability is examined in two ways, displayed in Figures 4 and 5. We examine whether the coefficient $b_{3}$ of lagged money growth in inflation equation 10 (Table 2,

reserves $z$. Column three refers to inflation equation 12 , and column four refers to unemployment equation 13.
${ }^{13}$ All of our data are from the data bank of the Federal Reserve Bank of St Louis, and our software package is MicroTSP 7.0

14The last two columns refer to the intermediate target system (discussed later) where the inpul is the growth of 
Figure 4

Recursive Estimate of the Coefficient of Lagged M2 Growth in Equation 10

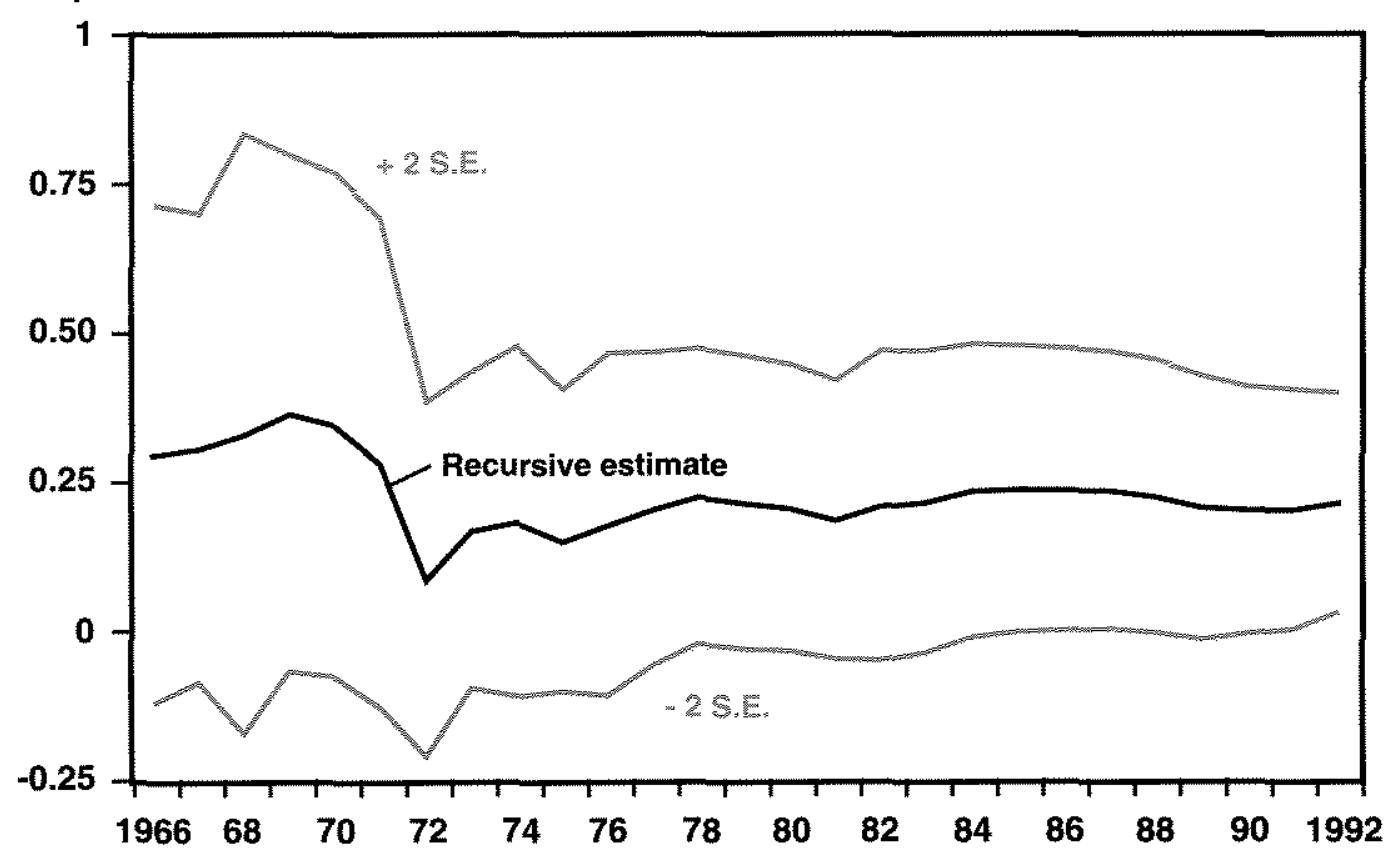

Figure 5

Dynamic Ex Ante Forecast of Inflation, Using Lagged M2 Growth as the Input

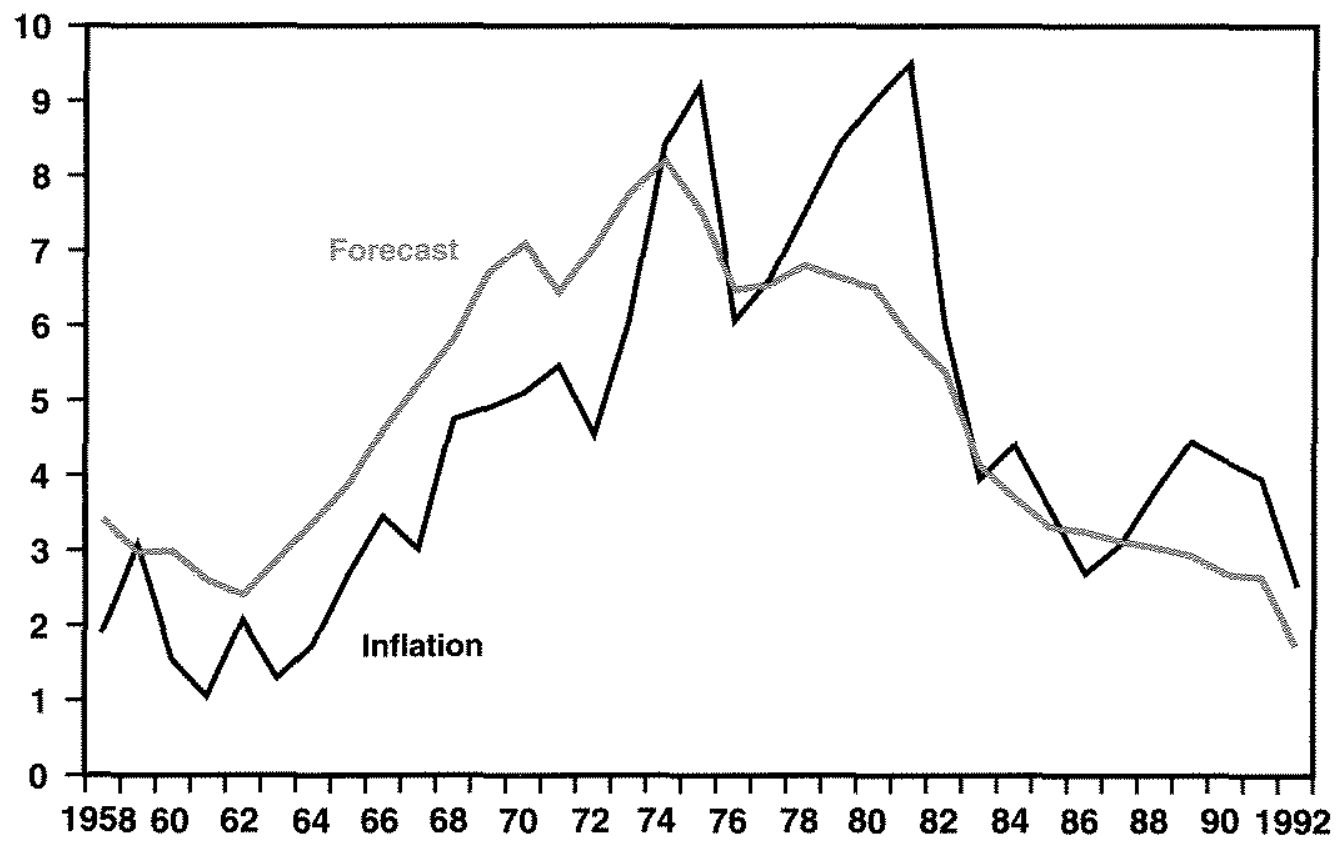


column one) is stationary or whether it evolves over time and responds to changes in the policy rule. Figure 4 is a recursive estimate of coefficient $b_{3}(t)$ using data through time $t$. If $b_{3}(t)$ displays significant variation as more data are added (as time increases), it is strong evidence of instability. If policy rule changes significantly affect the structure, the coefficient estimates will undergo dramatic changes. Figure 4 shows remarkable stability for coefficient $b_{3}(t)$, whereas the velocity series (Figure 3 ) show significant variation. The other coefficients in equation 10 (Table 2, column one) also are quite stable.

If the inflation equation using $\mathrm{M} 2$ is structurally stable, it should be useful for prediction: Otherwise, M2 is not an indicator. Figure 5 displays an $N$-period ahead dynamic forecast. There is never any correction for previous forecast errors. The graph INFM2 uses previously predicted values of the rate of inflation as the lagged dependent variable in the next prediction, but uses actual values of the lagged unemployment rate and rate of monetary expansion. ${ }^{15}$ It is necessary to know the state of the economy measured by $\mathrm{U}(t-1)$ as well as the rate of monetary expansion $\mu(t-1)$ to predict the subsequent rate of inflation $\pi(t)$. A comparison of the actual rate of inflation with the dynamic ex ante forecast using the growth of M2 as the input indicates that the actual rate converges to the predicted rate. Hence, equation 10 is structurally stable, policy-invariant and useful for prediction. Compare Figure 5 with Figure 2 to see the importance of knowing the state of the economy to predict inflation.

A unit root test on the growth of real balances $(\mu-\pi)$ indicated that it is stationary at a level of 2.8 percent per annum. That is $E(\mu-\pi)=2.8$ per annum. Since the steady state rate of inflation $\pi=\mu-n$, where $n$ is the long term growth rate, the estimates are sensible. From Table 2 column one, and the above, the half-life of the convergence of inflation to its steady state value $\mu-2.8$ is 3.47 years $^{16}$

15This is the FORCST command in MicroTSP.

16. Let the growth of real balances $\mu-\pi$ be denoted by $x$. The UROOT equation was $D x=2,1-0.75 x+0.4 D x(-1)$. The coefficient 0.75 is significant, UROOT $(\mathrm{C}, 1)=-4.3$ (Mackinnon 1 percent $=-3.6$. Hence, $x$ is stationary and will con. verge to the steady-state value $2.1 / 0.75=2.8$, used above. From Table 2, if the unemployment rate is at its equilibrium value, let $p$ be the deviation between the inflation rate and its steady state value: $D p=-.2 p$ (rounding). This implies that the half life is $T=\log 0.5 / \log 0.2=3.47$ years.
For all of these reasons, we therefore conclude that, within the context of difference equation 10: (1) The growth of M2 is a good indicator of inflation, and (2) there is no evidence that policy rule changes had any effects upon the relation between money (M2) growth and inflation in equation 10.

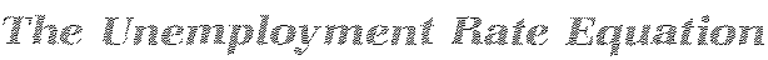

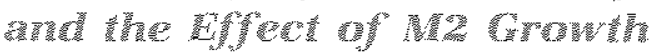

We have seen that, within the context of the SM model, the growth of M2 is a good indicator of inflation. In that equation, the change in the inflation rate depends positively upon the lagged growth of real balances which raises the excess demand for goods aggregate demand less current GDP) and negatively upon the state of the labor market measured by the lagged unemployment rate, which reflects the cost-push effects. Even if one knew the path of the growth of $\mathrm{M} 2$, it would be insufficient to predict the course of inflation, unless one could also predict the path of the unemployment rate. The omission of the unemployment rate is the main reason for the poor relation between the rate of inflation and the growth of M2 in Figure 2. To understand how the FOMC can achieve price stability and "sustainable growth in output," and how M2 growth affects both inflation and unemployment, we must examine the interactions between M2 growth, inflation and unemployment.

Table 2, column two, examines the unemployment rate equation 11 during the same sample period used for the inflation rate. It shows how the rate of growth of M2 affects the unemploy. ment rate and is perfectly consistent with the theory described above. The coefficients are subject to several constraints. The coefficient $a_{t}$ of the lagged unemployment rate must be less than unity for convergence to the equilibrium rate $V e=a_{0} /\left(1-a_{1}\right) \cdot{ }^{17}$ The coefficient of the lagged growth of real balances should be negative, since it produces the rise in aggregate demand for goods. This means that the coefficient $a_{2}$ of lagged inflation should be positive (raise unem-
1The mean unemployment rate $1957-92$ is 6 percent. The estimate of $a_{0}=1.9$ with a standard erfor of 0.55 . The estimate of $a_{1}=0.76$ with a standard error of 0.09 . If $a_{1}=0.7$ and $a_{0}=1.8$, then $U e$ is 6 percent. 
ployment) and coefficient $a_{3}$ of lagged monetary expansion should be negative (lower unemployment) and equal to $-a_{2}$. The neutrality constraint is $\left(a_{2}+a_{3}=0\right): A$ rise in the steady state rate of monetary expansion will produce an equal rise in the rate of inflation, and no change in the equilibrium unemployment rate.

Each coefficient has the correct sign and is significant at the 1 percent level. The neutrality hypothesis is satisfied. The probl$H_{0}: a_{2}+a_{3}=0$ I $=$ probl.29 $-.23=0]=0.46$ means that monetary factors cannot affect the steady-state unemployment rate. However, changes in the lagged rate of monetary expansion produce short-run changes in the unemployment rate. ${ }^{18}$

The equation (column two) passes the diagnostic tests. ${ }^{19}$ This equation is structurally stable over various policy regimes, and the equation has considerable predictive accuracy. Figures 6 and 7 indicate the predictive value and stability of the coefficients of the unemployment equation, despite the many changes in the policy regime. Figure 6 compares the actual unemployment rate with the rate forecasted from a dynamic ex ante simulation, where previously predicted values of the unemployment rate are used as the lagged dependent variable, but actual values are used for lagged inflation and growth of M2. The forecast refers to the equation in column two in which the input is the growth of $\mathrm{M} 2$. The actual rate of unemployment converges to the prediction. Figure 7 is a recursive estimate of the coefficient $a_{3}$ of the effect of the lagged rate of M2 growth. Despite the many changes in the policy rule used by the monetary authorities, this coefficient is remarkably stable. All of this evidence suggests that, if the policy variable is the rate of growth of M2, the policy ineffectiveness hypothesis is not in evidence. The structure of the model and values of parameters have been very stable despite changes in the policy rule used by the Federal Reserve, the deregulation of financial markets and the high mobility of international capital.

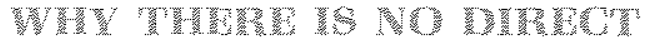

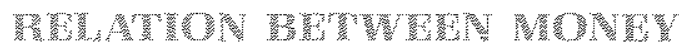

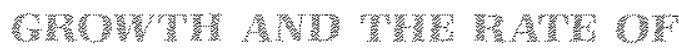

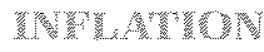

On the basis of the theoretical and empirical analysis, we may explain why Figure 2 shows no relation between the current rate of inflation and the current or lagged rate of money growth. From equations 10 and 11, we derive a phase diagram, Figure 8. From these equations and the coefficient estimates in Table 2 (rounded) columns one and two, derive equations 10.1 and 11.1. The curve $d \pi=d($ inflation $)=0$, which corresponds to equation (10.1), is the set of unemployment rates $u(t)=U(t)-U e$ and inflation rates $\pi(t)$, such that inflation is not changing. The curve $d u=d(u n e m p)=0$ is the set of unem ployment and inflation rates $s_{x}$ such that the unemployment rate is not changing; and it corresponds to equation 11.1.

$$
\begin{aligned}
(10.1) d(\text { inflation })= & \pi(t)-\pi(t-1)=-0.2[\pi(t-1) \\
& -\mu(t-1) I-0.4 u(t-1)=0 \\
(11.1) d(\text { unemp })= & u(t)-u(t-1)=0.25(\pi(t-1) \\
& -\mu(t-1)]-0.3 u(t-1)=0
\end{aligned}
$$

Let the rate of money growth (relative to capacity output) be $m$. Point $(m, 0)$ in Figure 8 is the steady state: where the unemployment rate $u=U-U e$ is zero, and where inflation is equal to money growth (relative to capacity growth). The curve $d$ (inflation) $=0$ is downward sloping for the following reason. When inflation is below $m$, there is a rise in real balances, which raises excess aggregate demand and hence the rate of inflation. To keep inflation from changing, there must be a rise in $u$ which reduces the cost-push element. The d(inflation) $=0$ is negatively sloped, and the directions of horizontal motion are towards the curve $d$ (inflation) $=0$.

The curve $d(u n e m p)=0$ is positively sloped for the following reason. Suppose that the

prob $=0.16$ indicates that there is no problem with heteroskedasticity and using the Ramsey RESET test, we do not find any evidence of misspecification.
18These results are inconsistent with the New Classical Economics, but are consistent wits basic monetarist (Friedman) views. Notice that we only work with measurable variables and do not use arbitrary and subjective estimates of anticipated or nonanticipated money growth. Belongia points out that the measure of unanticipated money growth is very sensitive to the monetary aggregate considered (as well as to what are the regressors in the equation for anticipated money growth).

19There is no evidence of serial correlation. The probability of the F-statistic that ail of the coefficients are zero is 0.00 , the adjusted $R$-square $=0.76 ; D W=2.0 ; \mathrm{ARCH}$ (2 lags) 
Figure 6

Dynamic Ex Ante Forecast of the Unemployment Rate, Using Lagged M2 Growth as the Input (Equation 11)

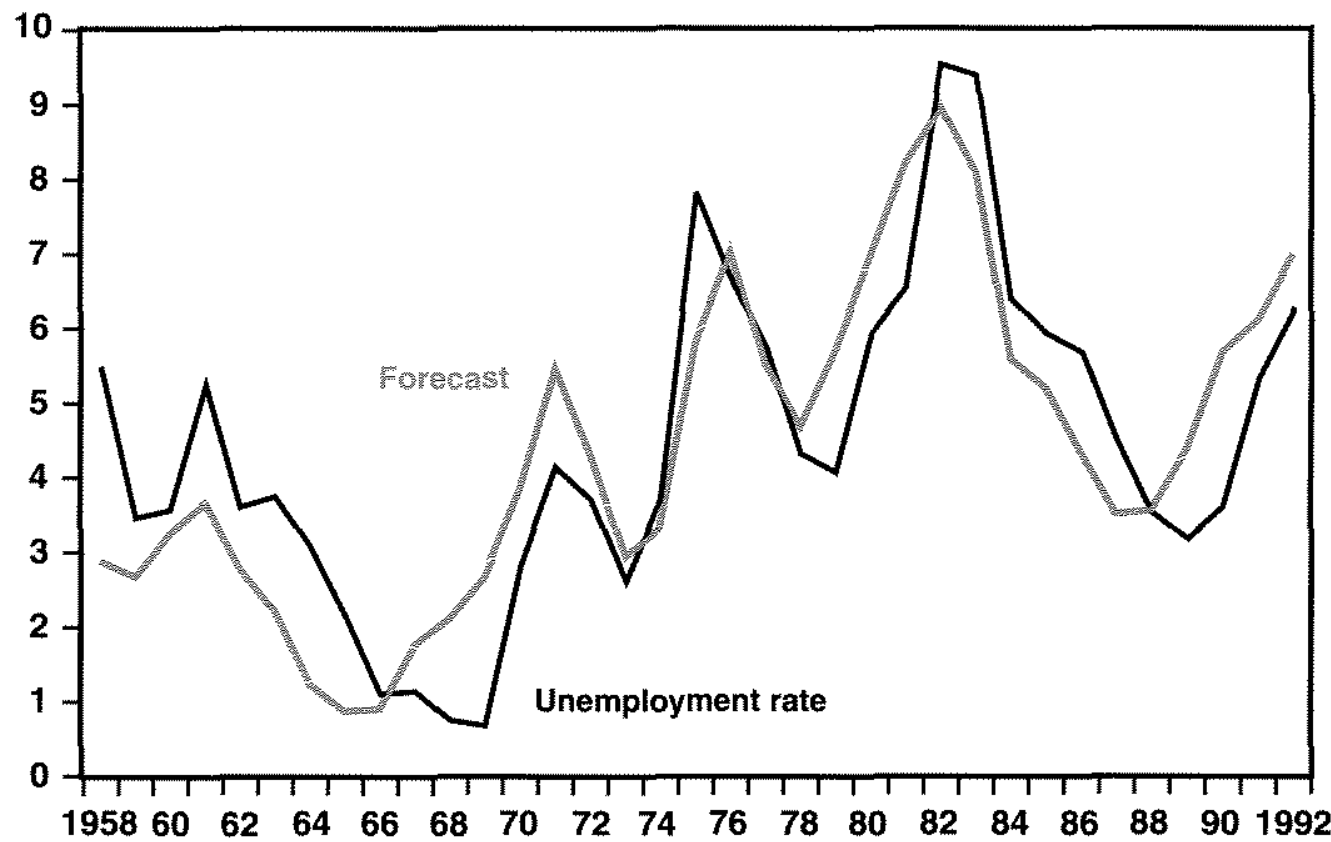

Figure 7

Recursive Estimate of the Coefficient of Lagged M2 Growth in Equation 11

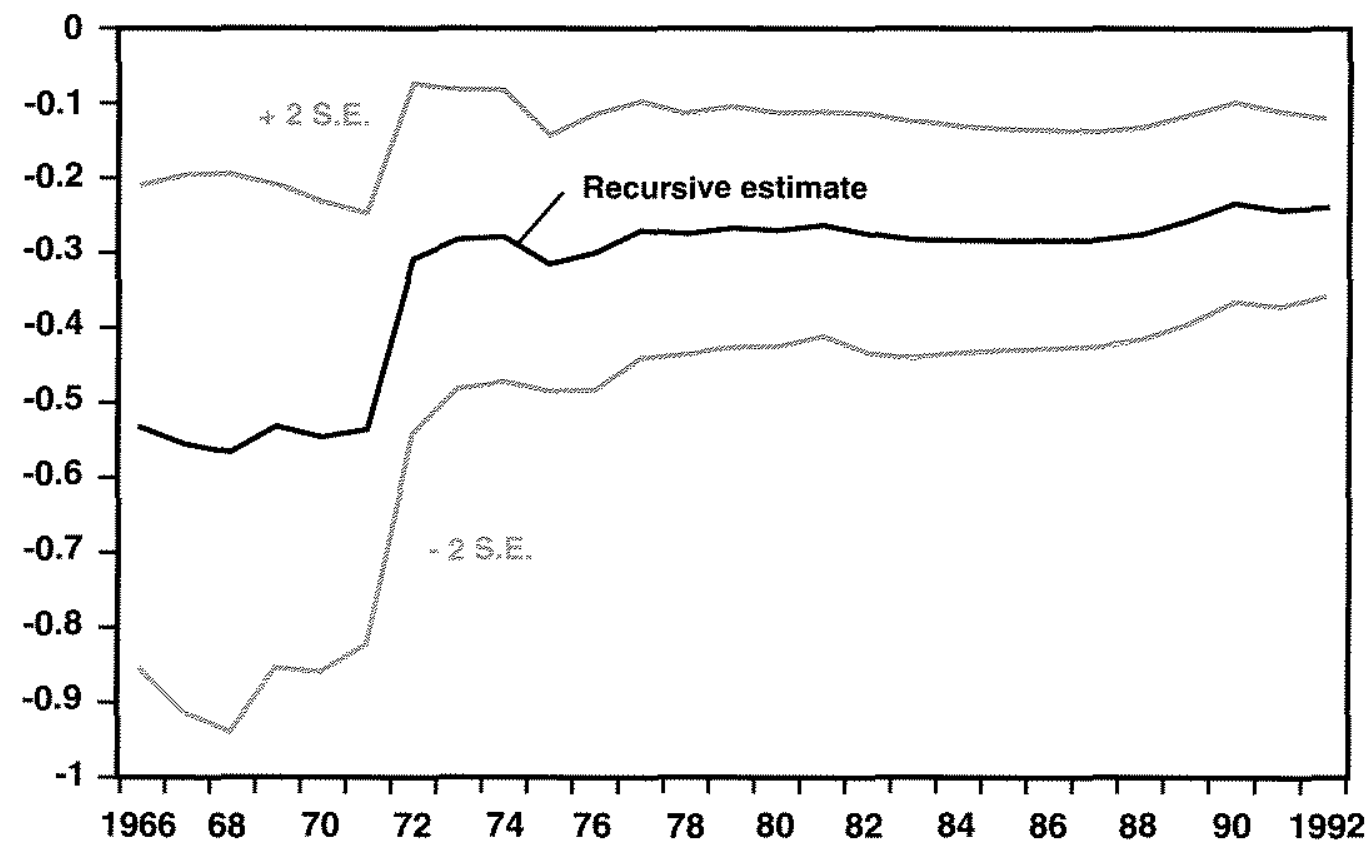




\section{Figure 8 \\ Phase Diagram}

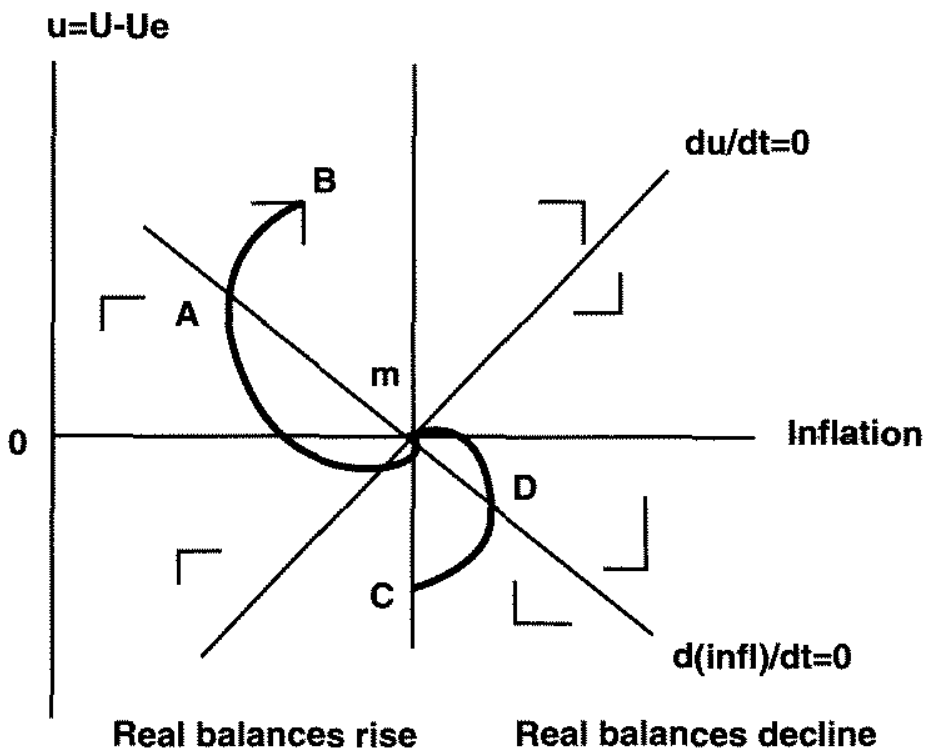

Note: Steady state is point $(m, 0)$, where $m$ is growth of M2 less long-term growth of the economy.

economy were at point $m$ and then the unemployment rate rose $(u>0)$. The rise in unemployment reduces the growth of nominal labor costs and real unit labor costs tend to decline. This will cause unemployment to decline. To keep $u$ from changing, aggregate demand must decline. A rise in inflation above $m$ will reduce real bal. ances which reduces aggregate demand. Therefore, the $d$ (unemployment) $=0$ curve is positively sloped. The vertical movement will be towards this curve, because above (below) it wages are growing at a smaller (greater) rate than prices.

With the phase diagram, we may answer two questions:

(1) Why do we find, as in Figure 2 , no relation between current or lagged money growth and current inflation?

(2) Will a rise in the rate of monetary expansion, designed to stimulate the economy, lead to higher inflation in the near future?

The answer to these questions depends upon where the economy is situated in Figure 8 . There are two variables:
(1) What is the deviation between the rate of inflation and the rate of monetary expansion? Where is the economy along the abscissa?

(2) What is the deviation between the unemployment rate and its equilibrium value? Where is the economy along the ordinate?

From any point, the system will converge to point $m$, where the unemployment rate is at its equilibrium value, and the rate of inflation is equal to the rate of money growth (relative to the trend rate of growth of the economy). The trajectories vary with the initial conditions. Given the estimates of the coefficients in 10.1 and 11.1 , the system will be damped cyclical. ${ }^{20}$

Consider two cases where money growth is $m$, but the initial conditions vary. We can explain why there is no relation between money growth and inflation in Figure 2. Suppose that, when the unemployment rate is above the equilibrium, an expansionary monetary policy is undertaken to accelerate the return to "full employment." The rate of monetary growth is raised above the inflation rate. The economy starts at point $B$.

\footnotetext{
20The characteristic equation implied by 10.1 and 11.3 is

$\lambda^{2}+.5 \lambda+.76=0$. The roots are complex, but the

system is stable.
} 
The trajectory will be $B A m$. Initially, along $B A$, both the inflation rate and unemployment rate decline. The weakness in the labor market more than offsets the effect of a rise in real balances upon aggregate demand, and the inflation rate declines. Wages decline relative to prices, and unemployment declines. Along $B A$, a rise in the rate of monetary expansion does not lead to more inflation. When the economy reaches point $A$, the lower unemployment rate implies that the weakness in the labor market is insufficient to offset the effect of a rise in real balances upon aggregate demand, and the inflation rate rises. Prices continue to rise relative to wages, and unemployment continues to decline. Along $A m$, the inflation rate rises though the unemployment rate is above its equilibrium level. ${ }^{21}$ Along trajectory $B A m$, the inflation rate declines and then rises for the same rate of money growth.

Similarly, suppose that the economy started at point $C$, where inflation is equal to money growth, but unemployment is below the equilibrium rate. Nominal wages will rise which will raise the rate of inflation. Wages will rise faster than prices, and the rise in real unit labor costs will increase unemployment. The economy moves along $C D$. At point $D$, the rate of decline of real balances lowers aggregate demand and offsets the wage-push effect. The rate of inflation declines, wages continue to grow faster than prices and the unemployment rate continues to rise. Along trajectory $C D m$, the inflation rate rises and then declines for the same rate of money growth.

We have explained why the rate of money growth is a good indicator of the rate of inflation only within the context of the dynamic system, equations 10 and 11 , where inflation and unemployment interact. No useful information about the rate of inflation is conveyed just by looking at the rate of monetary expansion per se as in Figure 2. If the rate of monetary expansion is raised to speed a recovery, this need not imply more inflation in the near

\footnotetext{
${ }^{21}$ This differs from the Keynesian NIRU view. See Modigliani and Papademos $(1975,1976)$. For a critique, see Caklson (1978) and Stein (1982, ch. 4). The analysis differs fundamentally from the New Classical propositions. Neither view is consistent with the results in Table 2.

22The importance of Divisia indices has been developed by Barnett. I am drawing upon Belongia $(1993 a, b)$ in the discussion of weighted monetary aggregates (WMA), who supplied me with the data to use as WMA in the SM dynamic model.

${ }^{23} \mathrm{~A}$ WMA is constructed as follows (See Belongia). Let $u_{i}(t)=\left[R(t)-r_{i}(t)\right] /[7+R(t)]$, where $R(t)$ is the return on a
}

future. The exact trajectories for inflation and unemployment implied by equations 10 and 11, in Table 2, columns one and two, are easily calculated.

\section{TIE USE OR WWICHWED

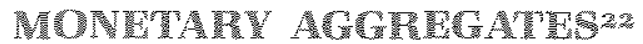

Several economists have argued that we know that the standard measures of monetary aggregates violate the basic principles of the economic theory of index numbers, because simple-sum measures incorrectly assume that the components are perfect substitutes and, hence, cannot internalize pure substitution effects. Belongia stated that "The potential for this sort of [substitution] shift in measured money, of course, is exactly the type of thing that may be behind the break in velocity and instability of money demand functions." The contention of Belongia, Chrystal and MacDonald (this Review) is that ostensible changes in the relationships between money growth and inflation observed in the 1980s, which have been subjectively attributed to "financial innovations" are simply due to improper measurements of the monetary aggregate. Instead of using ad-hoc, arbitrary measures of the "true" monetary aggregate, WMA have been constructed to internalize shifts among monetary aggregates based upon substitution effects. These are basically Divisia indices, by which the components of the WMA are weighed by their share of total expenditure on monetary services. $^{23}$

Their contention is not obvious. Figure $2 e$, graphs (along with the regression line) the rate of inflation against the growth of Divisia M2. There is no apparent relation between the two variables. Figure $3 \mathrm{~b}$ plots the velocity of Divisia M2 (nominal GDP divided by Divisia M2). The relation does not demonstrate any more stability than the velocities of M1 or M2 (Figure 3a).

long term grade B corporate bond, $r_{i}(t)$ is the asset's own rate of return. Denote the vector of the $u$ 's by $u=\left(u_{1}, \ldots, u_{n}\right)$, and the vector of the value of balances in the $j$-th asset category by $q=\left(q_{1}, \ldots, q_{n}\right)$. The weight $s_{j}(t)$ of the $i$-th asset is (b) $s_{i}(t)=u_{i}(t) q_{i}(t) / u(t) . q(t)$, where the denominator is an inner product. The weighted monetary aggregate WMA is (c) WMA(t) $=s(t) \cdot q(t)$. The period denotes the inner product operation. 
We examine the hypothesis that the WMA are the correct empirical counterparts of what is meant by money in the theory in the second section ${ }^{24}$ :

(1) The money should have the neutrality properties, noted alongside equations (10) and (11) above. A rise in the rate of monetary expansion should produce the same rise in the steady state rate of inflation. Equal changes in money growth and inflation should have no effect upon the unemployment rate.

(2) The WMA should satisfy the requirements for an indicator for both inflation and unemployment. It should be able to explain variations in the rate of inflation and how monetary policy exerts short-run changes upon the unemploy. ment rate. Specifically: Given information in year ( $t-1)$, to what extent can the WMA be used to predict inflation and unemployment in year $t$ ? The WMA have the desirable property that they are not arbitrary measures of "money-

ness." They have the limitation that their weights, which are interest rate differentials, are endogenous variables. When a monetary component is changed, the interest rate differentials change. Since the weights in the index change with the endogenous interest rates, the WMA is not a control variable and cannot be considered as an intermediate target.

We already analyzed $\mathrm{M} 2$ as an indicator in Table 2 for the sample period 1958-92. Table 3 compares three weighted monetary aggregates with M2 during the same sample period 1961-92, in terms of equations 10 and 11. The three WMA are used: $D M 2=$ Divisia $M 2 ; C E=$ Fotemberg's currency equivalent; $D C E=$ Divisia currency equivalent. In each case $\mu_{i}(t)$ is the rate of growth (percent per annum) of the aggregate. Our object is to see how each responds to points 1 and 2 above. Our conclusions, to be discussed, are:

(1) The M2 aggregate is the best of the potential indicators.

(2) The Divisia currency equivalent DCE is acceptable.

(3) The Divisia M2 (DM2) and the Currency Equivalent (CE) are unsatisfactory.
The upper part of Table 3 is inflation equation 10, and the lower part is unemployment rate equation 11. The entries are the regression coefficients and the two-tail significance levels in brackets. We also note the adjusted R-square and the probability implied by the LM statistic that there is no serial correlation.

Consider the successes. First is M2 in column one. In the inflation equation, the sum of the coefficients of lagged inflation and lagged M2 growth $(0.87+0.18)$ is not significiantly different from unity. Each coefficient is significant. In the unemployment equation, each coefficient is significant. The sum of the coefficients of lagged inflation and lagged M2 growth $(0.28-0.22)$ is not significantly different from zero. Second is the Divisia Currency Equivalent (DCE), which also passes these tests. However, the coefficients in the M2 equation are closer to their theoretical values than those in the DCE. The coefficients of lagged inflation and money growth should be equal and opposite in sign.

Next are the failures. The Divisia M2 (DM2) fails in the inflation equation. The coefficient of its growth $\mu$ is not significant. The currency equivalent (CE) fails in the unemployment rate equation. The coefficient of its growth $\mu$ is not significant. My conclusion is that $\mathrm{M} 2$ is the best of the indicators when it is used in the dynamic SM model, in which both unemployment and inflation interact.

A cogent analysis of the deficiency of Divisia indices of money has been given by Otmar Issing of the Deutsche Bundesbank (1992, p. 296). He wrote:

\footnotetext{
"In phases with an interest rate pattern in which the yield on time deposits is almost that on the yield on public bonds outstanding, time deposits to all intents and purposes disappear from the definition of the money stock (CE aggregates) or hardly contribute at all to money stock growth (Divisia Aggregates). Should time deposit rates exceed the yield on bonds outstanding; then this leads to either negative growth of these aggregates or the changed maximum interest rate is taken into con" sideration so that monetary capital components possibly contribute to growth in the money stock. The reason here is that - based on a utility max. imization approach - liquidity is measured in
}

24 It is essential that one have a macroeconomic theory to evaluate whether an empirical measure of money cor. responds to a theoretical concept. Barnett, Belongia and others correclly object to the ad hoc measures of "moneyness" that have been offered to replace M2. Many of these measures even fail to satisfy the neutrality requirement. 
Table 3

Inflation and Unemployment Equations Using Alternative Measures of Money

\begin{tabular}{|c|c|c|c|c|c|c|c|c|}
\hline Variable & \multicolumn{2}{|c|}{$1=42$} & \multicolumn{4}{|c|}{$\begin{array}{l}\text { Growth rate of the monetary aggregate } \\
\text { I= DWl }\end{array}$} & \multicolumn{2}{|c|}{$\mathrm{I}=\mathrm{CE}$} \\
\hline \multicolumn{9}{|c|}{ Inflation equation 13} \\
\hline Constant & 188 & {$[0.031$} & 215 & {$[002]$} & 2.44 & {$[0.00]$} & 178 & {$[0.05]$} \\
\hline$U(t-1)$ & 0,44 & $1000 \mid$ & -039 & 1001 & $-0,46$ & 10001 & 0,0 & {$[0.21]$} \\
\hline$\pi(t-t)$ & 087 & {$[0.00]$} & 090 & $000)$ & 097 & 0000 & 085 & {$[0.00]$} \\
\hline$\mu_{1}(t-1)$ & 018 & $0.045]$ & 013 & 10121 & 010 & 1007 & 0027 & {$[0.06]$} \\
\hline $\mathrm{ADJ} \mathrm{ASQ}$ & 079 & & 076 & & 078 & & 078 & \\
\hline$L M+p r o b$ & 0,14 & & 007 & & 0,1 & & 012 & \\
\hline \multicolumn{9}{|c|}{ Unemployment equation 14} \\
\hline Constant & 160 & 10001 & 1,19 & 10041 & 0.92 & {$[010]$} & 084 & {$[0.23]$} \\
\hline$U(t-1)$ & 081 & {$[0,00]$} & 0.75 & {$[000]$} & 0.80 & {$[000]$} & 068 & $000]$ \\
\hline$-(t-1)$ & 0.28 & 10001 & 0.26 & 10.001 & 018 & $1000]$ & 024 & {$[000]$} \\
\hline$\mu(t-1)$ & $-0,22$ & {$[0.00]$} & -015 & 10.0071 & $-0,10$ & 100081 & 0.001 & [092] \\
\hline$A B J A S Q$ & 082 & & 081 & & 078 & & 071 & \\
\hline$\angle M$ prob & 080 & & 076 & & 075 & & 0,65 & \\
\hline
\end{tabular}

Notes, The sample covers $196192 \mathrm{~N}=32$. The two-tall significance level is shown h brackets. The data are from the Federal Reserve Bank of St Louis, DM2 - Divisia M2, DCE $=$ Divisia currency equivalent, CE - currency equivalent.

terms of forfeited yields, while the dimension of risk - contrary to the portfolio optimization ap* proach - is not taken into account. The interest rate for a particular form of investment not only contains a premium for foregoing liquidity but also a risk premium owing to yield volatility. As empirical studies show, in particular the CE-M3 aggregate has in the past been subject to extreme fuctuations and the correlation with growth rates of GNP was in fact negative. Furthermore, the velocity of circulation of this aggregate was substantially more instable (sic) than that of M3."

The Divisia M2 is too much dependent upon endogenous weights, which are interest rate differentials, to be useful as an indicator of a theoretical concept of money. It misses the unique aspect of money that it is the safe asset used as the medium of exchange.

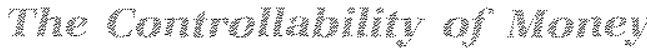 Guthory}

We have shown that growth of $\mathrm{M} 2$, denoted $\mu_{2}$, is a good indicator. There are two distinct is- sues: To what extent is money growth endogenous? To what extent is money growth controllable? In equation 14, part $C X$ is endogenous, $X$ is a vector of the state of the economy and $z$ is the growth of reserves. ${ }^{25}$ Unless variations in $\mu$ are controllable, they are not responsible for variations in inflation and unemployment; and the central bank does not have the wherewithal to control inflation. in the medium run. ${ }^{26}$

(14) $\mu_{2}=C X+b z+e$

We can relate total reserves $R$ to $M 2$. There is a close relationship between reserves $R$ and M1, through a system of reserve requirements. Call the reserve requirement ratio $R / M 1=a$. We can then write:

$R / M 2=(R / M 1)(M 1 / M 2)=a(M 1 / M 2)$

and therefore,

$\log M 2=\log (M 2 / M 1)+\log R-\log a$.

${ }^{25}$ For notational simplicity, let e generically represent the random variable with a zero expectation.

26 In the long run, as Figure 1 indicates, the price level is still closely tied to M2/real GDP. 


\section{Figure 9 \\ Ratios of M2 to the Adjusted Monetary Base and Adjusted Reserves}

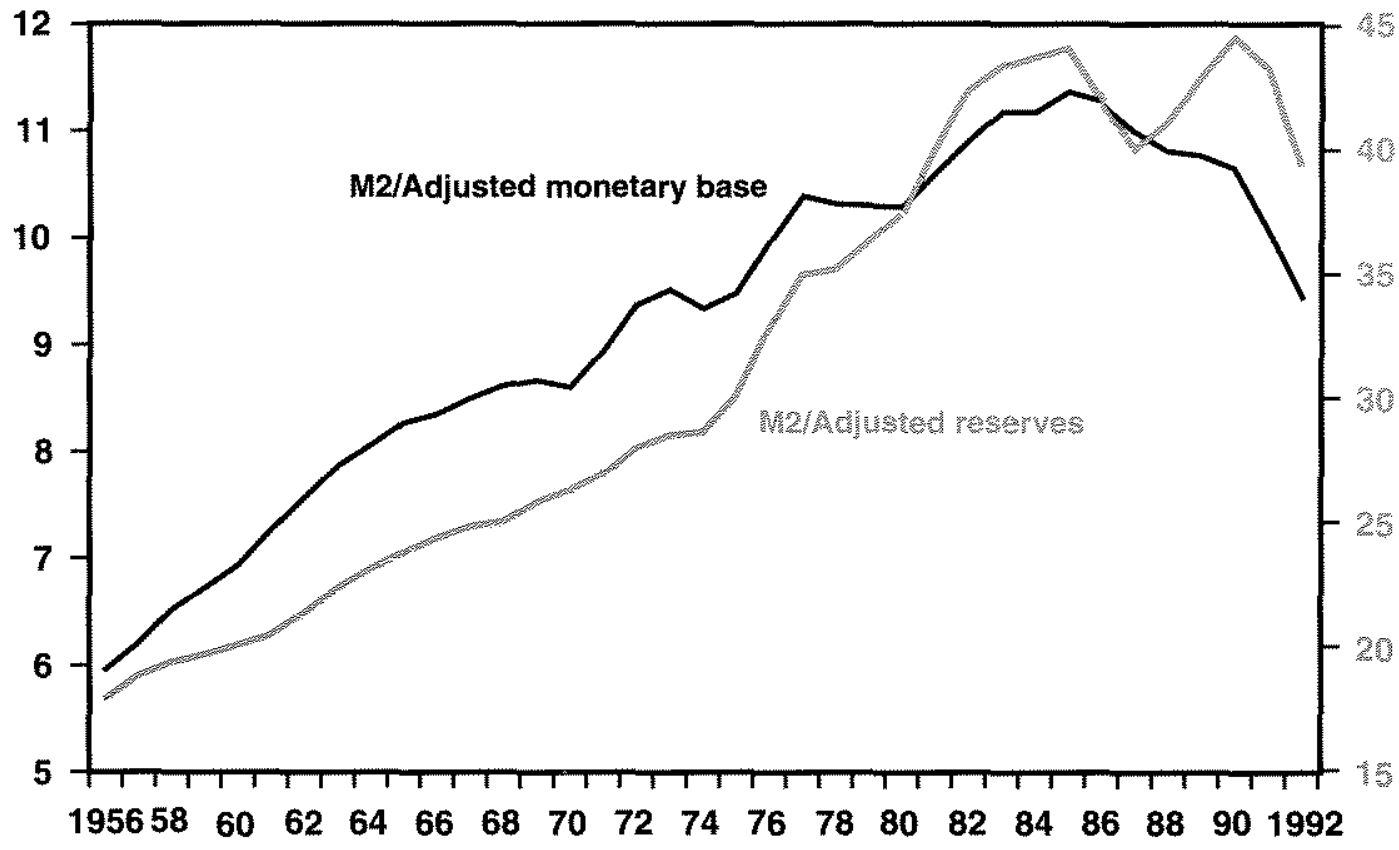

The rate of change of $M i(i=1,2)$ is denoted $\mu_{i}$ and the growth of reserves is denoted $z$. Thus, we have equation 15 , which we relate to equation 14:

(1.5) $\mu_{2}=\left(\mu_{z}-\mu_{1}\right)+z+e$

(14) $\mu_{2}=C X+b z+e$

The growth of M2 in equation 15 has three components: the growth in adjusted reserves $\mathrm{z}$, which is controllable; the growth in the non-M1 component of $\mathrm{M} 2$, which is $\left(\mu_{2}-\mu_{1}\right)$; and the $e$ term, which reflects nonsystematic factors. ${ }^{27}$ Thornton noted several points. First, the Fed has a tight control on $M 1=R / a$ via reserves. Second, the ratio of M1 to M2 declined from 0.5 in 1959 to 0.25 in 1977 , and has then fluctuated around this level. Third, the policy variable, which is the growth of reserves, does not have a significant effect upon $\left(\mu_{2}-\mu_{1}\right)$. The Fed can control only the M1 component of M2 but can" not control the other component $\left(\mu_{2}-\mu_{2}\right)$ directly. For example, suppose that a rise in fiscal policy or private demand tends to raise the growth of nominal GDP, which induces a growth in the demand for money. The given growth of reserves controls the growth of M1. There will be a growth in $\mathrm{M} 2$ relative to $\mathrm{M} 1$ to accommodate the induced rise in the demand for money. This means that $C X=\left(\mu_{2}-\mu_{1}\right)$ is endogenous; and it may well be the major source of variation of the rate of money growth in equation 15.

Figure 9 suggests that there has been a structural break in the controllability of the growth of M2. The graph is the ratio of M2 to adjusted reserves. It has a relatively constant positive trend until 1975. The trend rises drastically to about 1984. Then it falls to zero or becomes negative. A similar situation exists with the ratio of $\mathrm{M} 2$ to the adjusted monetary base. We shall now be more precise.

We consider two components of money growth in equation 16 which correspond to 14 and 15.

(16) $\mu_{z}=c^{\prime} D N G D P(-1)+b z+e$

The control part is the controllable growth of reserves. The induced part is related to the lagged growth of nominal GDP, denoted

27The controllability of $\mathrm{M} 2$ is the subject of the important

paper by Thornton (1992), upon which we draw. 
Table 4

The Rate of Growth of M2 as a Function of the Lagged Growth of Nominal GDP and the Growth of Adjusted Reserves (Equation 16)

\begin{tabular}{|c|c|c|c|}
\hline Vartable & 1958,92 & $1958-75$ & 197592 \\
\hline Constant & $360(002)$ & $3401001]$ & $2,10 \mid 0,45]$ \\
\hline DNODP $(-1)$ & $0,311005 \mathrm{I}$ & $=004[071]$ & 05610041 \\
\hline l 2 का का & $027(0,06)$ & $090 / 000$ & 0,1710099 \\
\hline DW $n$ & $1 / 0 \mathrm{n}$ & $1,69 \quad \mathrm{al}$ & $1,10 \mathrm{an}$ \\
\hline$A D J A-S O$ & 012 & 064 & 014 \\
\hline
\end{tabular}

Note, the two-tail significance level is shown in brackets.

DNGDP $(-1) \cdot{ }^{28}$ The induced part corresponds to $C X$ in equation 14 . That means that if the omitted fiscal variables and shocks to private demand induce a rise in the demand for money, the growth of M2 will respond, although the growth of M1 is tied to the growth of reserves.

There are several implications from Table 4 , which are consistent with Thornton's findings. ${ }^{29}$ First, consider column two, which concerns the early period $1958-75$. The growth of reserves is the significant determinant of the growth of $\mathrm{M} 2$, with a coefficient 0.9 , which is not significantly different from unity. The growth of lagged nominal GDP is not significant ${ }^{30}$ A regression of $\mu_{2}$ on $z$ and a constant gives almost the identical results, during the first period. Hence one could confidently claim that $\mu_{2}=c+Z+e$, where $c$ is a trend which corresponds to the growth of M2/M1. The money supply was both controllable and the controllable part was the dominant component. Hence from 1958 to 1975 , the growth of M2 was an intermediate target for both the inflation and unemployment rates. This is "Monetarism Triumphant."

Second, consider column one containing the entire period 1958-92. It would seem that both the growth of reserves and the growth of nominal GDP are significant. However, the equation evaluation tests tell a different story. The recur'sive residuals (not shown) keep moving outside the plus-or-minus-2 standard error bands, which implies that the structure is progressively changing. Figure 10 is a recursive estimate of the coefficient of the growth of reserves. This coefficient has a clear downward trend from unity towards zero, indicating that the control part is becoming less significant since the mid-1970s. The reason is shown in column three containing the period 1975-92. This column is a direct contrast to column two the $1958-75$ period. The growth of reserves is not significant. The lagged growth of nominal GDP is significant. However; the regressors only explain 14 percent of the variation in the growth of M2. During the period 1975-92, it is not apparent that the growth of M2 was an intermediate target.

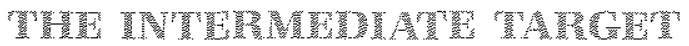 SWG}

It is quite possible that we have omitted sig" nificant variables from the induced part $\mathrm{CX}$ of money growth, so that it seems that money growth is no longer controllable by the growth

\footnotetext{
${ }^{28}$ The lag is used to avoid a simulaneous equation problem. We also used for the induced part the Treasury bill and Treasury bond rates, which could reflect changes in the structure of interest rates, which would ultimately induce substitutions between $M 1$ and M2. However, they were not significant additions to the growth of reserves.

29Similar results were obtained when the regressors were the lagged unemployment and inflation rates.

30The equation for this period passes all of the equalion evaluation tests: There is mo serial correlation (LM test) heteroskedasticity (ARCH test).
} 
Figure 10

Recursive Estimate of the Coefficient of the Reserves Growth in Equation 16

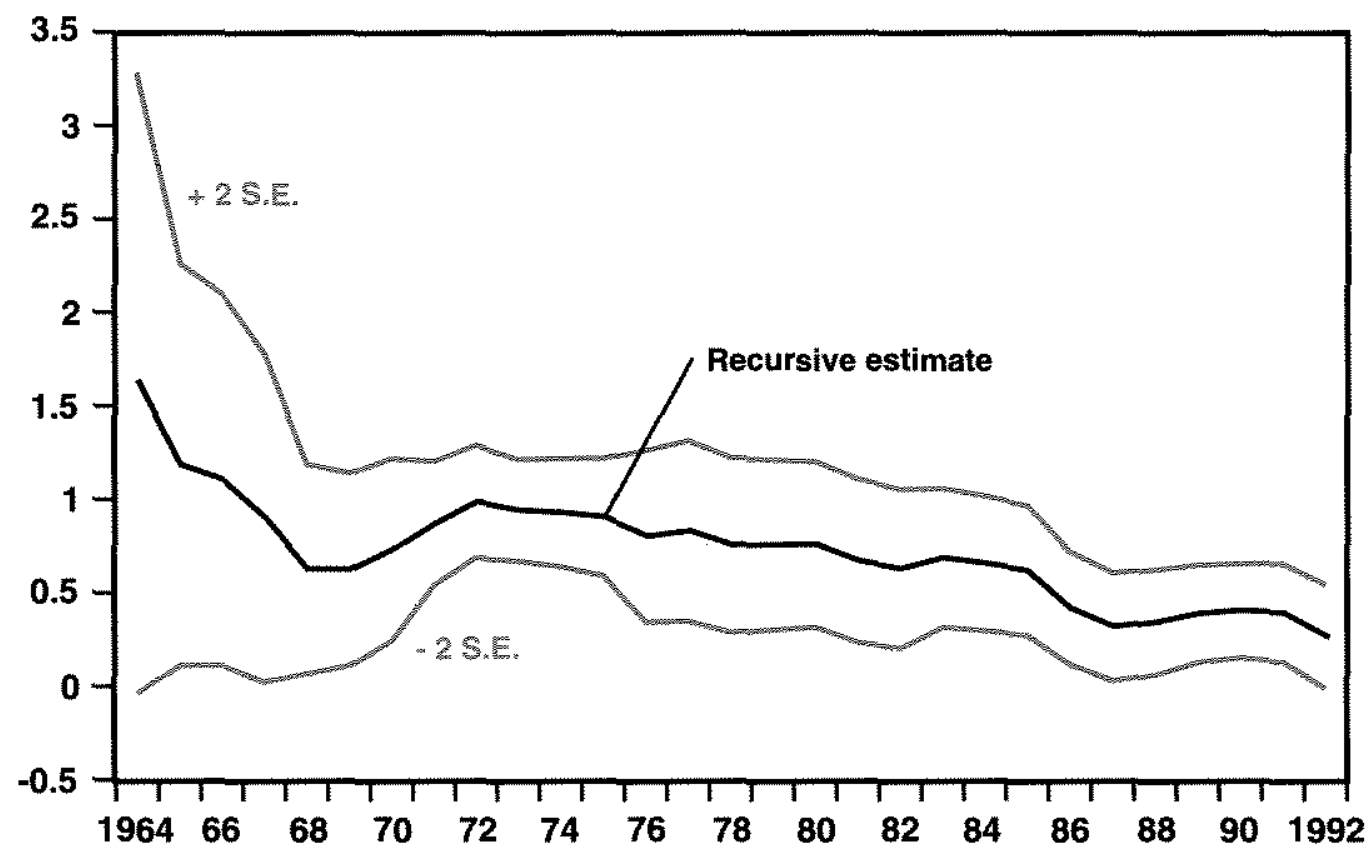

Figure 11

Dynamic Ex Ante Forecast of Inflation, Using Lagged Resources Growth as Input (Equation 12)

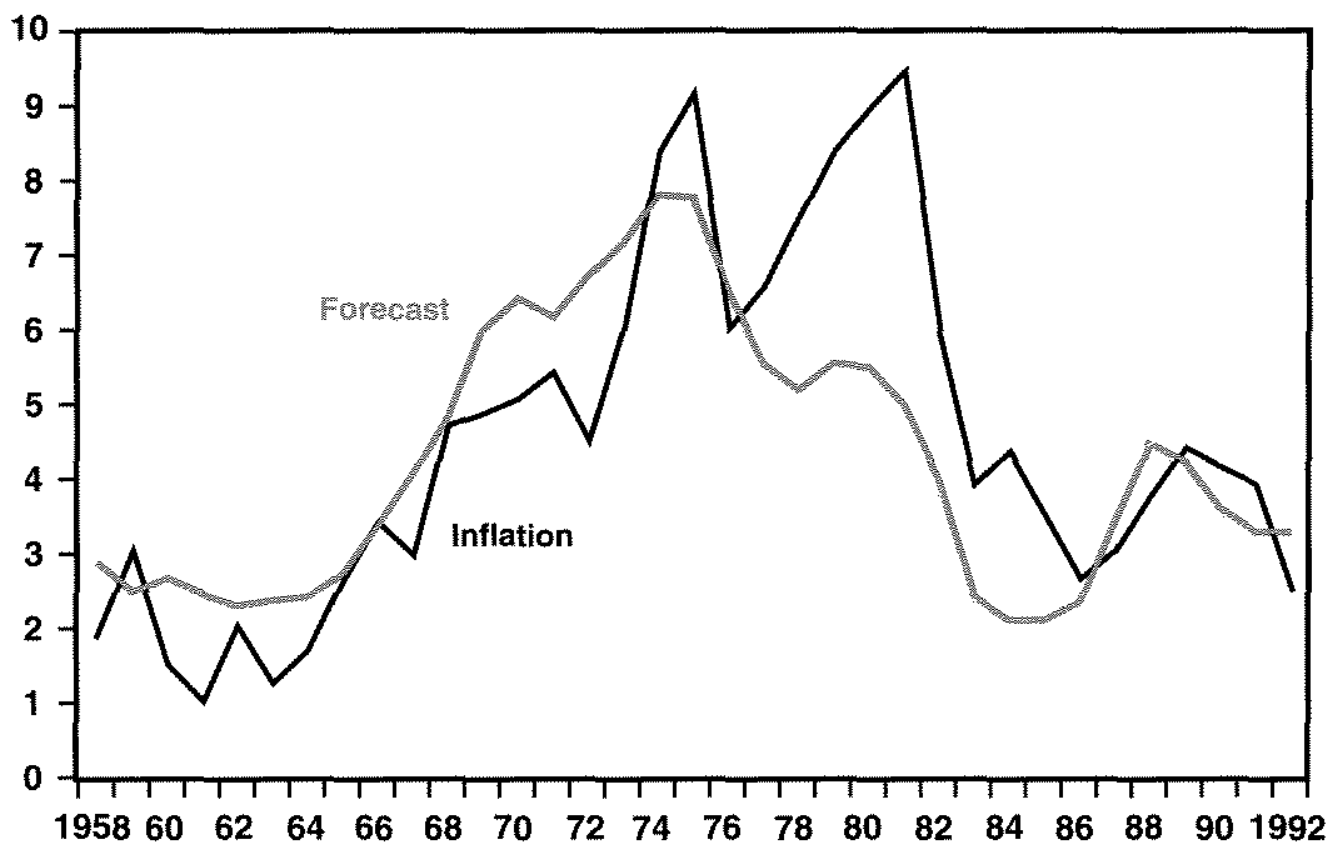


Figure 12

\section{Recursive Estimate of the Coefficient of Lagged Reserves Growth in Equation 12}

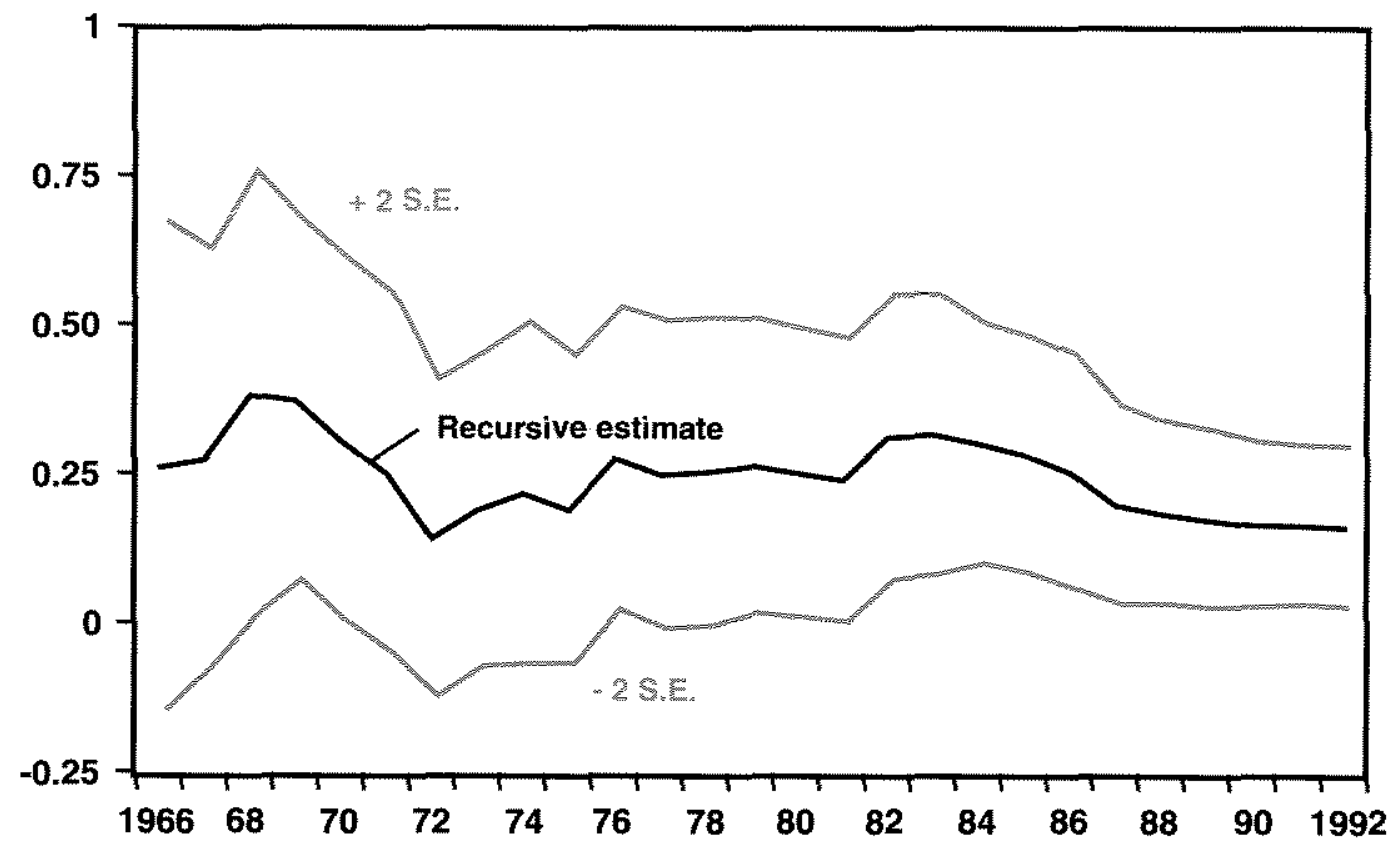

of reserves. The control equations involving the growth of reserves were described in the second flow chart, shown here again:

$$
\begin{aligned}
X<--D X= & (A+B C) X+(B b)_{Z} \\
& +\left(B e^{y}+e^{1}\right)<----Z
\end{aligned}
$$

\section{intermediate target control variable}

A direct test of controllability is equations 12 and 13 , in the surrogate system, estimated in Table 2, collumns three and four:

(12) $\pi(t)=b_{0}^{\prime}+b_{1}^{\prime} U(t-1)+b_{2}^{\prime} p(t-1)$

$$
\begin{aligned}
& +b_{3}^{\prime} z(t-1)+e ; \\
& H_{0}: b_{2}^{\prime}+b_{3}^{\prime}=1 ; b_{x}^{\prime}<0
\end{aligned}
$$

(13) $U(t)=a_{0}^{r}+a_{1}^{\prime} U(t-1)+a_{2}^{\prime} \pi(t-1)$

$$
\begin{aligned}
& +a_{z}^{\prime} z(t-1)+e ; \\
& H_{0}: a_{z}^{\prime}+a_{3}^{\prime}=0 ; a_{3}^{\prime}<0
\end{aligned}
$$

Call this the control system. The next two sections show that the controllable growth of reserves may be a good intermediate target for the rate of inflation. The subsequent section shows that the short-term Treasury bill rate, which may be controllable, has no informational content; it is neither an indicator nor an intermediate target. Interest rate targeting, which has had disastrous results both in the Great Depression and the pre-1979 periods, is to be avoided at all costs.

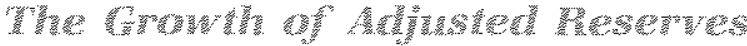 楞路 A}

In the control system, the control input is $z$ the growth of adjusted reserves. This variable is

31We did not use the growth of the adjusted monetary base as the control variable for two reasons. First, it failed to satisfy the neutrality requirement. Second, it is not a reliable control over the growth of M1 due to the significant variations in the currency ratio. See Garfinkel and Thornton. 
clearly controllable. ${ }^{32}$ We evaluate whether the control system is structurally stable and policyrule-invariant, when there have been changes in Federal Reserve operating procedures and policy, and financial market deregulation. Table 2 , columns three and four, and the subsequent analysis show that the control system is quite significant for the inflation rate but less so for the unemployment rate.

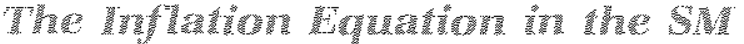

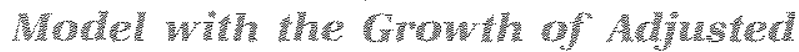

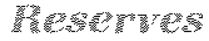

The inflation equation is 12 . The rate of infla tion rises when (1) real reserves rise, the growth of reserves exceeds the current rate of inflation, or (2) when the labor market is tight, the unemployment rate is below its equilibrium rate. In the steady state, the rate of inflation will rise by the same amount as the rise in the growth of reserves. Real reserves converge to a constant. This is the neutrality hypothesis $b_{z}^{\prime} b_{3}^{\prime}=1$ in 12. The second factor states that the coefficient of the lagged unemployment rate is negative.

Table 2, column three, is consistent with these hypotheses. Fach coefficient is significant and has the hypothesized $\operatorname{sign}^{33}$ The Adj, $R-S Q=0.78$. The neutraity hypothesis is confirmed. It is seen with a Wald test that the sum of the coeffi. cients of the inflation and growth of reserves is not significantly different from unity: prob $l b_{2}^{\prime}+$ $\left.b_{3}^{\prime}=1\right]=$ prob $[0.92+0.16=1]=0.44$.

We show in several ways that this equation is structurally stable and policy-invariant. First, Figure 11 compares the actual rate of inflation with a dynamic ex ante forecast derived from Table 2, column three, denoted INFRES. The large deviations for the 1977-80 period are corrected by 1986 ; and the model is back on track. Second, Figure 12 displays the structural stability in a clear and dramatic way. It is a recursive estimate of coefficient $b_{3}^{\prime}$ which relates the effect of a change in $z(t-1)$ the growth of reserves in year $t-1$ upon $\pi(t)$ the rate of inflation in yeas $t$, given the initial values of unemployment and inflation. This coefficient is fairly stable, despite the changes in policy regime over the period. The conclusion is that the growth of adjusted reserves is an intermediate target for achieving price stability, within the context of the dynamic equation.

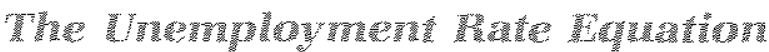

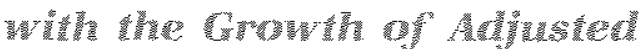

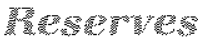

The inflation equation is not sufficient to answer the question: How can the central bank achieve price stability and "promote sustainable growth?" The reason is that the inflation rate is affected by the state of the unemployment rate as well as by its past history and the growth of reserves. Attempts to reduce the rate of inflation by varying the growth of reserves will affect, in the medium run, the unemployment rate. In turn, the unemployment rate will affect the inflation rate. Another dimension to this problem concems whether monetary policy can also affect, in the medium run, the unemployment rate, and what will be the consequences for the rate of inflation?

We turn to equation 13 in Table 2, column four, to see to what extent the growth of reserves affects the unemployment rate. Table 3 , column four, is consistent with several hypotheses. First,

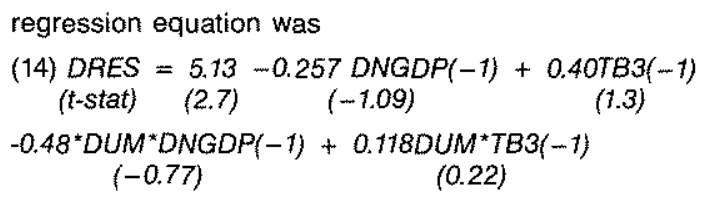

$A D J$ R-squared $=0.00$. No coefficient is significant and there is no evidence that the growth of reserves has been an endogenous variable in any significant way during the period $1959-92$

33There is no evidence of either serial correlation (LM test prob $=0.18$ ) or heteroskedasticity (ARCH test $p r o b=0.49$ ). The Ramsey RESET test of whether there are omitted variables, incorrect functional form or correlation between the regressors and the error term indicates that the probability that there is no specification error is 0.38 
Figure 13

Dynamic Ex Ante Forecast of the Unemployment Rate, Using Lagged Resources Growth as the Input (Equation 13)

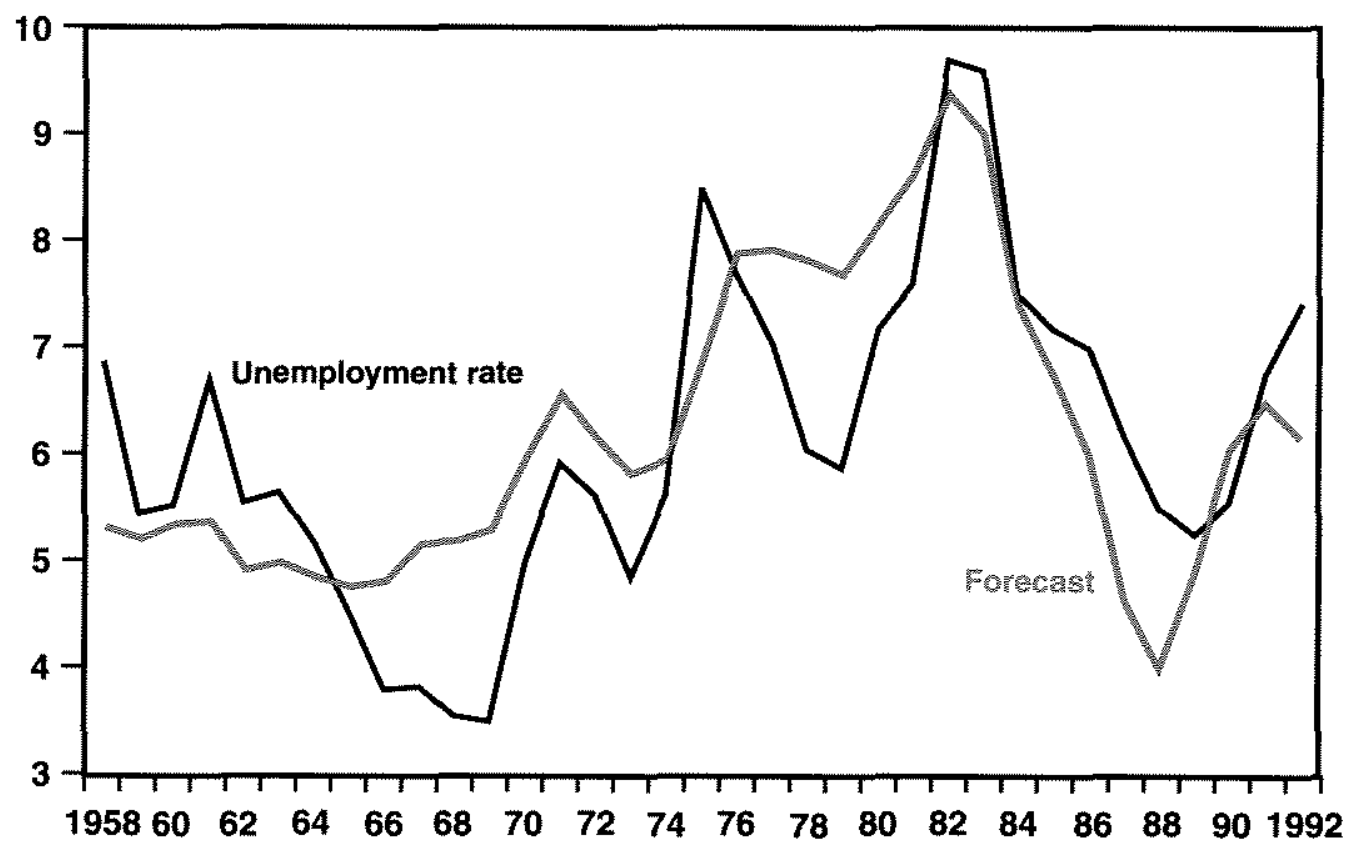

Figure 14

Recursive Estimate of the Coefficient of Lagged Reserves Growth in Equation 13

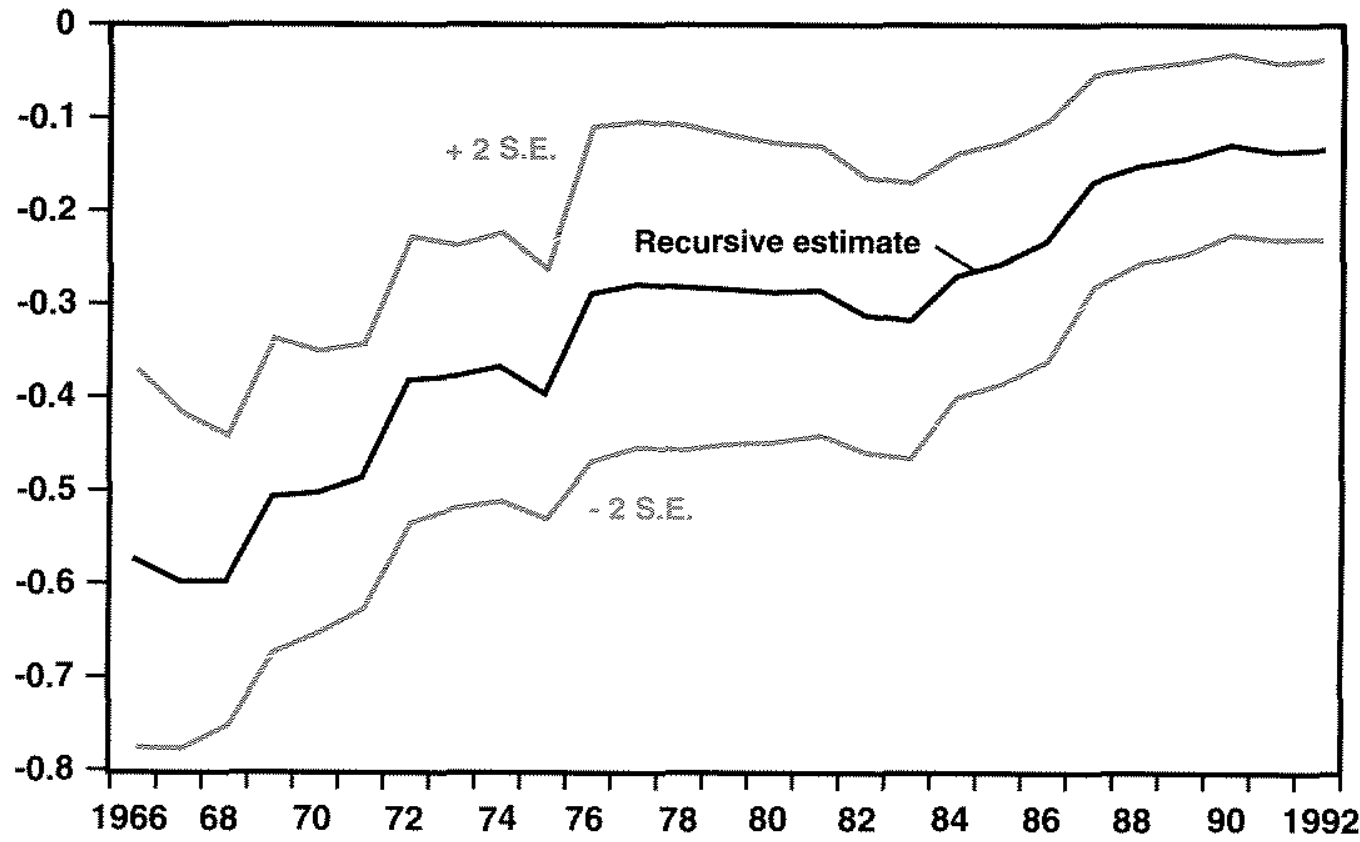


each coefficient has the correct sign and is significant at the 1 percent level; and the $R^{2}=0.71 .^{3.4}$ Second, the neutrality hypothesis is confirmed. When reserves rise at the same rate as the rate of inflation, there is no effect upon the unemployment rate, which would then converge to its equilibrium rate. Hence, $a_{2}^{\prime}+a_{3}^{\prime}=0$, that is, the coefficients of inflation and the growth of reserves sum to zero. Using a Wald test, the Prob $\left[a_{2}^{\prime}+a_{3}^{\prime}=0\right]=$ Problo.23 $\left.-0.13=0\right]=0.23$, thereby confirming the neutrality hypothesis.

Third, the explanatory power of this equation is much less satisfactory than the inflation equation where the input is the growth of M2. In Figure 13, the actual unemployment rate is compared with a dynamic ex ante simulation of the value implied by the coefficients in Table 2 , column four, where the lagged dependent variable is the previously predicted value. The forecast predicts basic trends but gives misleading predictions of the level of the unemployment rate.

Fourth, Figure 14 plots the recursive estimate of the coefficient $a_{3}^{\prime}<0$ of the lagged growth of reserves. The absolute value of this coefficient has been diminishing over the sample period. ${ }^{35}$ A possible reason for the decline in importance of the growth of reserves in the unemployment equation may be that the growth of reserves has become a less important deter. minant of money growth (Figure 13) in a period when the non-M1 component of M2 has become more important.

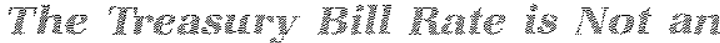

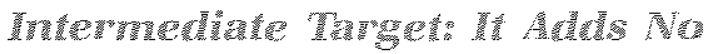

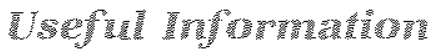

The Federal Reserve has revived the issue of interest rate targeting, where the Treasury bill rate is an intermediate target. Is there evidence to support interest rate targeting? The Treasury bill rate, denoted $i_{1}$, is controllable. Hence, it should be used to evaluate interest rate targeting. The surrogate dynamic SM model implied equations 12 and 13 . If interest rate targeting

${ }^{34}$ There is no evidence of serial correlation (LM test $p r o b=0.72$ ) nor of heteroskedasticity (ARCH test prob $=0.64$ ). According to the RESET test, there is no evidence of misspecification (RESET test prob $=0.12$ ).

351 do not have an explanation why the coefficient $a_{3}<0$ in Figure 9 is stable, but $a_{3}<0$ is not in Figure 14.

36lf there is real interest rate targeting, the only available information concerns observed, not anticipated, rates of inflation. It requires prescience for the monetary authority to makes any economic sense, the interest rate should be a significant input into the dynamic inflation and unemployment rate equations, either by itself $[\delta=0]$ or as additional informan tion $/ \delta=1 /$ to the growth of $\mathrm{M} 2$, in equations (12.1) and (13.1).

$$
\begin{aligned}
& (12.1) \pi(t)=c_{1}+c_{2} U(t-1)+c_{3} \pi(t-1) \\
& +d c_{4} \mu(t-1)+c_{5} i_{t}(t-1)+e \\
& \text { (13.1) } U(t)=c_{1}^{\prime}+c_{2}^{\prime} U(t-1)+c_{3}^{\prime} \pi(t-1) \\
& +\delta c_{4}^{\prime} \mu(t-1)+c_{5}^{\prime} i_{1}(t-1)+e^{t}
\end{aligned}
$$

Since the rate of inflation is a regressor, a rise in the nominal interest rate in the regression corresponds to a rise in the observed real rate ${ }^{36}$ Table 5 describes the results of such a test. Column one is the inflation equation, which just uses the Treasury bill rate as a control $l \delta=0$ ) It is seen that the coefficient of the Treasury bill rate is not significant. It contains no additional information about what will happen to inflation. Column two adds the growth of M2 as an input $I d=1]$. The growth of M2 is highly significant (as it was in Table 2), and the Treasury bill rate remains insignificant. The conclusion here is that adding the Treasury bill rate adds no infor. mation about what will happen to inflation.

Columns three and four concern the unemployment rate. In column $3 / \delta=0 /$, the results are bizarre. The coefficient of the nominal interest rate is not significant at the 5 percent level, and the coefficient of inflation is not significant. Given the nominal interest rate, a rise in the rate of inflation corresponds to a decline in the real rate of interest. This should lower the unemployment rate, but it does not. Therefore, it would appear that real interest rate targeting is not promising. In column four, we add the rate of $\mathrm{M} 2$ growth $[\delta=1]$. The results turn sensible for everything but the Treasury bill rate, which continues to remain insignificant. The conclusion is that the Treasury bill rate at $(t-1)$ adds absolutely no information to what is obtained from the results in Table 2.

use estimates of anticipated inflation that cannot be objectively justified. It is not clear whether the spread between the bond rate and Treasury bill rate is a more or less accurate measure of anticipated inflation than is the recent ex post inflation. In either case, the onus of finding the true ex ante real rate is upon the advocates of interest rate targeting. 
Table 5

Inflation and Unemployment Rate Equations

\begin{tabular}{|c|c|c|c|}
\hline & Equation 12:1 & \multicolumn{2}{|c|}{ Equation $13 ;$} \\
\hline Variable & & & \\
\hline Constant & $\pi(0)(\delta=0) \therefore$ & $U(U) I \delta=d)$ & Uf $10=t]$ \\
\hline$U t t-1)$ & $1.39 \quad[0.12]$ & $1.27[0,05]$ & $189 \quad 1000$ \\
\hline$\pi(t-1)$ & $-0,39 \quad[0.018]$ & 0.5610 .00 & $072 \quad[0,00]$ \\
\hline$(t-1)$ & $0.858[0.00]$ & $0.12[0.18]$ & $0.226[0.01]$ \\
\hline$\mu(f-1)$ & $-0.059[0.61]$ & 0.15 (0.07) & $0.079[0.27]$ \\
\hline
\end{tabular}

Note Sample period is $1958-92 \mathrm{~N}=35$. The two-tail significance is shown in brackets

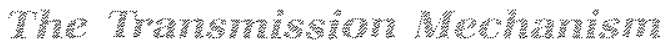

There is a good reason why the Treasury bill rate is neither an indicator nor an intermediate target. This concerns the transmission mechanism. Aggregate investment demand depends upon the Keynes-Tobin $q$-ratio. Monetary policy exerts its effects upon the economy through this ratio. Keynes (1936, p. 151) explained the theory of the q-ratio: "...the daily revaluations of the stock exchange, though they are primarily made to facilitate transfers of old investments between one individual and another, inevitably exert a decisive influence on the rate of investment. For there is no sense in bullding up a new enterprise at a cost greater than that which a simlar enterprise can be purchased; while there is an inducement to spend on a new project what may seem like an extravagent sum, if it can be floated off on the stock exchange at an immediate profit." ${ }^{\prime 3}$

Formally, let $q: k$ be the market value of $k$ the existing capital and let $p . k$ be the reproduction cost. ${ }^{3}$ Their ratio is the $q$-ratio.

(17) $q=q^{\prime} \cdot k / p \cdot k$

The portfolio balance equation 18 is that the ratio of money to the market value of capital $M / q: k$ depends upon $L(i)$ where $i$ is a vector of opportunity costs $i=\left(i_{1}, \ldots, i_{n}\right)$, and element $i_{i}$ is the perhaps controllable Treasury bill rate. Solve equation (18) for $q=q^{\prime} k / p \cdot k$, which is associated with portfolio balance and obtain 19. Denote
$m=M / p \cdot k$, the ratio of real balances per unit of capital.

(18) $M / q: k=M / q p k=M / p k / q=L(i)$

(19) $q=[M / p \cdot k] / L(i)=m / L(i)$

Monetary policy, which changes reserves, operates as follows in the context of equation 19. Let there be a rise in real bank reserves, which is a control variable. The higher ratio of reserves to deposits induces banks to purchase financial assets, equity or debt. The greater willingness to lend induces their customers to borrow to purchase equity and debt. The money stock rises. Given the vector of expected returns $i$ on the $n$-assets, the prices of existing assets, real and financial, rise. This is a rise in the Keynes-Tobin $q$-ratio, the ratio of the prices of existing assets (stock prices, bond prices, physical plant), relative to their reproduction costs. This encourages the production of investment goods and raises the excess demand for goods relative to current GDP. ${ }^{39}$ This is the logic of having $m$ in equation 19 above: It reflects the $q$ ratio effect. The rise in $q=q^{\prime} \cdot k / p, k$ need not be reflected in the Treasury bill rate or in any particular interest rate. Changing the Treasury bill rate without changing the growth of $M 2$ has a negligible effect upon the $q$-ratio, whereas changing the money stock has a large effect, assuming that both are controllable. Interest rate targeting of the Treasury bill rate prow vided a misleading indicator of what has been
37The role of financial markets in capital formation, along these lines, is the theme of Stein $(1987, \mathrm{ch} .7 ; 1991, \mathrm{ch} .3)$.

38The period represents an inner product. Variables $q ; k$ and $p$ are vectors of market prices, physical quantities and reproduction costs, respectively. Capital and bonds are in vector $k$ and the weighted sum is $q^{\prime} k$. This is definitely in the spirit of Keynes and Tobin.
39This is not the textbook transmission mechanism, but it is the one stressed by Keynes, Tobin and Friedman. 
happening to the q-ratio, or the stance of monetary policy, as was stressed by Friedman and Schwartz in their account of the Great Contraction. ${ }^{40}$

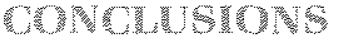

In the long run, the GDP deflator is closely related to the quantity of M2 per unit of real GDP. ${ }^{41}$ The question examined in this paper concerns how the Federal Reserve should select ranges for monetary growth over the coming year to achieve a given rate of change in the price level in the near future. Our conclusions were stated as propositions $A-D$ at the beginning of the paper. Friedman does not think that the inflation rate can be controlled finely:

"...we cannot predict at all accurately just what effect a particular monetary action will have on the price level and, equally important, just when it will have that effect. Attempting to control directly the price level is therefore likely to make monetary policy itself a source of economic disturbance because of false stops and starts ...Accordingly, I believe that a monetary total is the best currently available immediate guide or criterion for monetary policy-and I believe that it matters much less which particular total is chosen than that one be chosen (1969, p. 1089)...there seems little doubt that a large change in the money supply within a relatively short period will force a change in the same direction in income and prices...But when the money changes are moderate, the other factors come into their own. If we knew enough about them

and about the detailed effects of monetary changes, we might be able to counter these effects by monetary measures. But it is utopian given our present level of knowledge. There are thus definite limits to the possibility of any fine control of the general level of prices by a fine adjustment of monetary change." (p.181)

Friedman's argument should be qualified, in view of the analysis in this paper. First, the choice of the monetary aggregate does matter. No aggregate has the same quality of explanatory power as does M2, within the context of the dynamical system. Second, there is a serious question whether the growth of M2 is controllable. From 1958 to 1975 , the growth of M2 was controllable. The equation for its growth was a constant (which is the trend) plus the growth of reserves plus an error. From 1975 to 1992, the link between the growth of M2 and the growth of reserves was no longer apparent.

What should be the Federal Reserve's control policy, since the link between M2 growth and reserve growth after 1975 is not apparent? We concluded that:

(1) The growth of M2 is a good indicator within the context of the dynamic model. However, it is doubtful that it is controllable in the medium run.

(2) The Federal Reserve should place greater weight upon its control of inflation, than upon the attempt to fine-tune the economy, because the inflation equation in the reduced form system has more stability and predictability than does the unemployment equation in that system. ${ }^{42}$

\footnotetext{
toOne of the most vivid examples of the dangers of interest rate fargeting, inspired by Friedman and Schwartz, is shown below, which compares 1929 with 1932 . The data are from the U.S. Department of Commerce; the appropriate series are noted. The first row is the S\&P index (B85), the second row is the implicit price deflator $P^{r}$ for fixed investment ( $B 68$ ), the ratio of the two is an index of the $q$-ratio. The founth row is it, the Teasury bill rate (B83). The variable 12 is the basic yield of 30 -year corporate bonds ( $B 75$ ). Variable i3 is the Manhattan real estate mortgage rate (B78). The row labelled $P$ is the implicit GNP deflator (B63) and $M$ is the money supply (B110), The average annual rate of growth of $P$ and $M$ is in square brackets in the 1932 column.

The movement in the treasury bill rate was a misleading measure of the extent that the $q$-ratio changed.

$\begin{array}{lcc} & \text { The Great Depression Period } \\ \text { variable } & 1929 & 1932 \\ \text { S\&P index } & 26.02 & 6.93 \\ \text { Price investment good } & 39.4 & 31.6 \\ \text { qratio index } & 0.66 & 0.22 \\ \text { treasury bill (1) } & 4.42 \% \mathrm{pa} & 0.88 \% \mathrm{pa} \\ \text { 30 yr corp (i2) } & 4.22 & 4.7 \\ \text { mortgage rate (i3) } & 5.92 & 5.75 \\ \text { GNP deflator P } & 50.6 & 0.2[-7.67 \% \mathrm{pa}] \\ \text { Money stock } & 26,419 & 20,689[-8.15 \% \mathrm{pa}]\end{array}$
}

41 See Figure 1. There is also a close long-run relation between M2 and the quantity of adjusted reserves, and, hence, a long-run relation belween the GDP deflator and the ratio of adjusted reserves per unit of real GDP. These relationships look similar to Figure 14. However, none of these three relationships passes the usual cointegration tests.

42Hall (p. 278) wrote: "I conclude that established models are unhelpful in understanding this recession [1990-92] and probably most of its predecessors." Insofar as the growth of M2 was controllable prior to 1975 , the $\mathrm{SM}$ dynamic model does explain the recessions. See Figure 6 above. However, after 1975 it is not clear that the growth of M2 is controllable. Hence, the good fit in Figure 6 after 1975 does not contradict Hall. 
(3) Friedman's admonitions concerning fine tuning with respect to money, which is not obviously controllable, should apply to fine tuning of the reduced form system using the controllable growth of reserves. Mathematically, Friedman's argument is that given the uncertainty concerning the values of the parameters in Table 2 as reflected in their standard errors, the central bank should be most reluctant to vary its control variable in pursuing its objective of price stability lest growth be adversely affected. However, an optimal control policy in this context has not as yet been established. ${ }^{43}$

\section{PIETHENGES}

Barnett, W.A., E. Offenbacher and P. Spindt. "The New Divisia Monetary Aggregates," Journal of Political Economy (December 1984), pp. 1049m85.

Belongia, Michael T. "Measurement Matters: Recent Results from Monetary Economics Re-examined," mimeo, University of Mississippi, 1993a.

"Consequences of Money Stock Measurement: Evidence from Three Countries," presented at meetings of the American Statistical Association, August 8-10, 1993b. , and Dallas S. Batten. "Selecting an Intermediate Target for Monetary Policy When the Goal is Price Stability," Federal Reserve Bank of St. Louis Working Paper 92-008A (October 1992).

Carlson, Keith. "Inflation, Unemployment and Money: Comparing the Evidence from Two Simple Models;" thes Review (September 1978), pp. 2-6.

Friedman, Miston. The Optimum Quantity of Money, and Other Essays. Aldine Publishing Co, 1969.

and Anna J. Schwartz. A Monetary History of the United States 7867-1960. Princeton University Press, 1963
Garfinkel, Michelle, and Daniel L. Thornton. "The Link Between MI and the Monetary Base in the 1980s," this Review (September/October 1989), pp. 35-52.

Greenspan, Alan. 1993 Monetary Policy Objectives: Summary Report of the Federal Reserve Board. Board of Governors of the Federal Reserve System, 1993.

Hall, Robert E. "Macro Theory and the Recession of 1990-91," The American Economic Review (May 1993), pp. 275-79.

Intante, E.F., and Jerome L. Stein. "Money Financed Fiscal Policy in a Growing Economy," Journal of Political Economy (April 1980), pp. 259-87.

issing, Otmar. "Theoretical and Empirical Foundations of the Deustche Bundesbank's Monetary Targeting," Intereconomics (November/December 1992), pp. 289-300.

Keynes, J.M. The General Theory of Employment, Interest and Money. Harcourt Brace, 1936.

Modigliani, Franco, and L. Papademos. "Monetary Policy for the Coming Quarters: The Conflicting Views," Federal Reserve Bank of Boston New England Economic Review (March/April 1976), pp. 2-35. , and Targets for Monetary Policy in the Coming Year, Brookings Papers $1,(1975)$, pp. 14t-63.

Ritter, Joseph A. "The FOMC in 1992: A Monetary Conun" drum," this Review (May/June 1993), pp. 31-49.

Stein, Jerome L. "Cobwebs, Rationat Expectations and Futures Markets," Review of Economics and Statistics (February 1992a), pp. 127-34. "Price Discovery Processes," Economic Record, special issue (1992b). International Financial Markets. Blackweli, 1991. The Economics of Futures Markets. Blackwell, 1986. Monetarist, Keynesian and New Classical Econom. jcs. New York University Press, 1982.

Thornton, Daniel L. "Targeting M2: The Issue of Monetary Control," this Review (July/August 1992), pp. 23-35.

United States Department of Commerce. Long Term Economic Growth 1860-1965. Bureau of the Census, U.S. Government Pinting Office, 1966.

\footnotetext{
43The reason is that the coefficients of the dynamical system - equations 11, 12 and Table 2 (columns three and four) - are stochastic, with significant standard errors which do not go to zero as the sample size increases. This problem is being studied at present by Wendell Fleming (Department of Applied Mathematics, Brown University) and the author.
} 


\section{Appendix}

\section{Use of Quarterly Data in Estimating the Dynamic SM Model}

The results in the table below indicate why we used annual data in our empirical analysis. Inflation is measured relative to the previous quarter, but at an annual rate. The growth of M2 is measured in the same manner. The effects build up over time and quarterly movements per se have no significance.

Consider first columns one and two, which correspond to equations 10 and 11 . In the inflation equation (column one) only the lagged dependent variable is significant at the 5 percent level. The lagged money growth is significant at the 8 percent level, but the equation fails to satisfy the neutrality constraint. Theoretically, in an equation such as 10 , regardless of the time span, the sum of the coefficients of lagged inflation $\left(b_{2}=0.75\right)$ and lagged money growth $\left(b_{3}=0.08\right)$ should sum to unity. The null hypothesis that $b_{2}+b_{3}=1$ has a probability level of 0.014 ; hence, the neutrality (null) hypothesis is rejected. In addition, there is very serious serial correlation of the residuals. The LM statistic, using three lags, where the null is no serial correlation, has a probability of 0.00 . The ARCH test rejects homoskedasticity at the 3 percent level.

Column two relates to equation 11. At first glance, the results are significant. However, there are difficulties. First, the coefficient of the lagged unemployment rate $(0.98)$ is not significantly different from unity, and the constant is not significantly different from zero. Thus, if in. flation equals money growth, the unemployment rate converges to zero. Second, there is serious serial correlation of the residuals. Using lags up to two quarters, the LM test of no serial correlation has a probability of 0.00 . Third, the ARCH test of no heteroskedasticity has a probability of 0.00 . So the unemployment equation in column two fails using these diagnostics. The conclusion is that we cannot have confidence in the results of columns one and two.

Columns three and four consider two lags of inflation and money growth, where time is measured in quarters. This means that a span of half a year is being considered. The main results are that nothing of significance, other than the effects of its own lagged variable, is apparent by focusing upon quarters rather than upon annual data. The only significant variables in the inflation equation (column three) are the lagged inflation rates one and two quarters. The one-quarter lagged money growth is not significant. The lagged two-quarter money growth is significant at the 8 percent level. So, nothing much shows up within two quarters. Second, in the unemployment rate equation (column four), the lagged dependent variable is significant. Inflation during the previous two quarters is not significant. The money growth in the previous quarter is not significant. However, the money growth two quarters earlier is significant. Compare Table 2 in the text with the table above. These are the reasons why we used annual data in the analysis in the paper.

\section{Table A1}

\section{Inflation $\pi$ and Unemployment $U$ Equations (10-11)}

\begin{tabular}{|c|c|c|c|c|c|}
\hline Variable & Equation 10 & Equation 1 & Equation 10 & \multicolumn{2}{|c|}{ Equation 11} \\
\hline Constant & $0.91[0.12]$ & $0.21 \quad[0.12]$ & $0.76[0.16]$ & 0.26 & $10.04]$ \\
\hline$U(1-1)$ & $-0.07[0.50]$ & $0.98 / 10001$ & $-0.15[0,1]$ & 099 & {$[0.00]$} \\
\hline$(t-1)$ & $0,750.00)$ & $0,036[0,00]$ & $0,42[0,00)$ & 0.02 & 10.211 \\
\hline$\pi(t-2)$ & + & 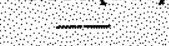 & $044[0.001$ & 0.03 & {$[0,14]$} \\
\hline$\mu(t-1)$ & $0.08[0083]$ & $-0032[000]$ & 0.0110841 & 80002 & {$[086]$} \\
\hline$\pi(t-2)$ & 12 & +ै। & $0.09[008]$ & 005 & [0oo] \\
\hline
\end{tabular}

Notes, Quarterly data M2 Growth is the input, The sample is $1956.4-1992.4$ The two tail significance is shown in brackets. 